\title{
Promoting parent-child interaction and communication for healthy development of adolescents: Lessons from a pilot project in rural Bihar
}

Shireen J. Jejeebhoy

Population Council

A.J. Francis Zavier

Population Council

K.G. Santhya

Population Council

Santosh Kumar Singh

Population Council

Rajib Acharya

Population Council

See next page for additional authors

Follow this and additional works at: https://knowledgecommons.popcouncil.org/departments_sbsr-pgy

Part of the Demography, Population, and Ecology Commons, Family, Life Course, and Society

Commons, and the International Public Health Commons

How does access to this work benefit you? Let us know!

\section{Recommended Citation}

Jejeebhoy, Shireen J., A.J. Francis Zavier, K.G. Santhya, Santosh Kumar Singh, Rajib Acharya, Aparajita Gogoi, and Vinita Nathani. 2014. "Promoting parent-child interaction and communication for healthy development of adolescents: Lessons from a pilot project in rural Bihar." New Delhi: Population Council. 


\section{Authors}

Shireen J. Jejeebhoy, A.J. Francis Zavier, K.G. Santhya, Santosh Kumar Singh, Rajib Acharya, Aparajita Gogoi, and Vinita Nathani 


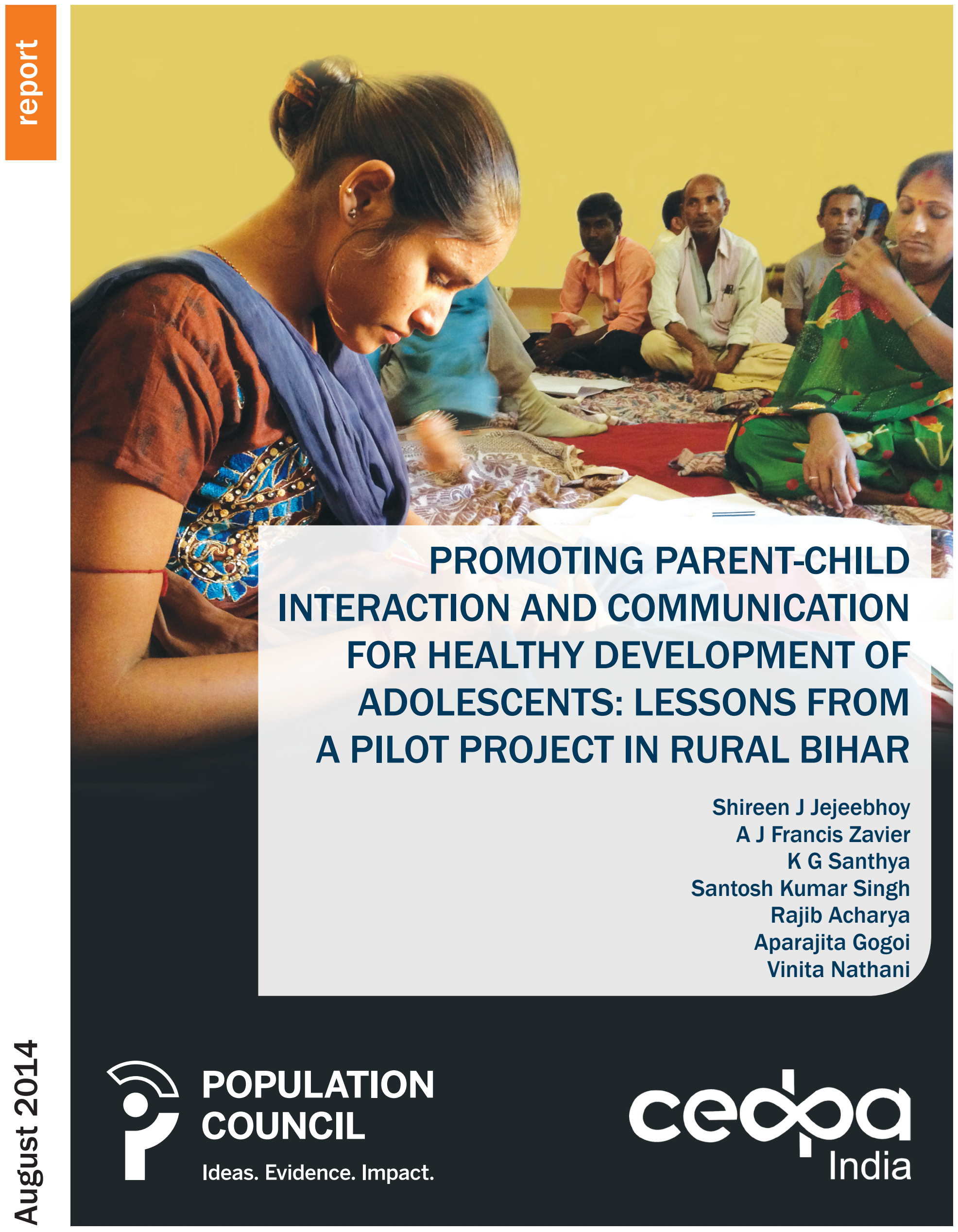




\section{2 population COUNCIL}

Ideas. Evidence. Impact.

The Population Council confronts critical health and development issues-from stopping the spread of HIV to improving reproductive health and ensuring that young people lead full and productive lives. Through biomedical, social science, and public health research in 50 countries, we work with our partners to deliver solutions that lead to more effective policies, programs, and technologies that improve lives around the world. Established in 1952 and headquartered in New York, the Council is a nongovernmental, nonprofit organization governed by an international board of trustees.

\section{Population Council}

Zone 5A, Ground Floor

India Habitat Centre, Lodi Road

New Delhi, India 110003

Phone: 91-11-24642901

Email: info.india@popcouncil.org

Website: www.popcouncil.org

\section{cépa}

The Centre for Development and Population Activities (CEDPA India) is a non-governmental organization registered under the Societies Registration Act, 1860. CEDPA India's focus is on increasing educational opportunities for girls and youth; ensuring access to lifesaving reproductive health information and services; and strengthening women's ability to become leaders in their communities and nation.

\section{CEDPA India}

C-1, Hauz Khas

New Delhi - 110 016, India

Tel: +911147488888

Email: contact@cedpaindia.org

Website: http://www.cedpaindia.org/

Suggested citation will also change to: Jejeebhoy. S. J., A. J. F. Zavier, K. G. Santhya et al., 2014. Promoting parent-child interaction and communication for healthy development of adolescents: Lessons from a pilot project in rural Bihar. New Delhi: Population Council. 


\section{PROMOTING PARENT-CHILD INTERACTION AND COMMUNICATION FOR HEALTHY DEVELOPMENT OF ADOLESCENTS: LESSONS FROM A PILOT PROJECT IN RURAL BIHAR}

Shireen J Jejeebhoy

A J Francis Zavier K G Santhya Santosh Kumar Singh

Rajib Acharya Aparajita Gogoi Vinita Nathani

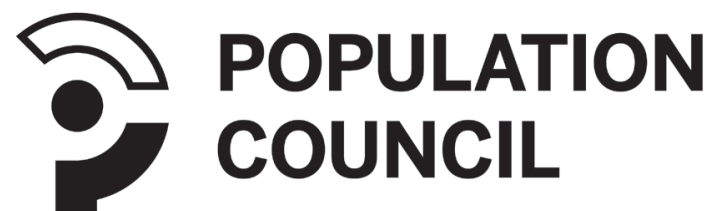

Ideas. Evidence. Impact.

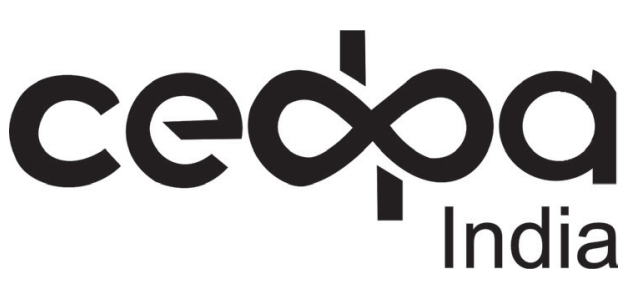




\section{Table of Contents}

List of Tables

List of Figures

Acknowledgements

Chapter 1 Introduction

Chapter 2 Profile of the lives of parents and adolescents

Chapter 3 Exposure to and perceptions about the intervention

Chapter 4 Effects of the intervention: Parental knowledge, attitudes, socialisation practices and parent-child communication

Chapter 5 Summary and recommendations

Appendix 1 Calculation of standard of living index

Appendix 2 Background characteristics of parents by exposure to the intervention (had attended at least two sessions), baseline survey 


\section{List of Tables}

Table 1.1: Socio-demographic indicators, Bihar state and Bhojpur district

Table 1.2: Response rate at baseline and reasons for non-response

Table 1.3: Follow-up rates in endline survey and the reasons for loss of sample in the follow-up

Table 2.1: Selected household characteristics and individual characteristics of parents (mothers and fathers) of 13-17-year-old adolescents, and of the adolescents (daughters and sons aged 13-17), baseline survey

Table 2.2: Percentage of parents reporting awareness about various aspects of physical maturation and other SRH matters, baseline survey

Table 2.3: Percentage of parents reporting egalitarian gender-role attitudes

Table 2.4: Percentage of parents perceiving that girls and boys should have a say in marriage-related decisions

Table 2.5: Percentage of parents agreeing that daughters and sons should be given information on various matters

Table 2.6: Percentage of parents reporting adherence to traditional norms on parent-child communication about SRH matters

Table 2.7: Percentage of parents reporting parental and adolescent shyness about parent-child communication about SRH matters

Table 2.8: Percentage of parents reporting encouragement of children's agency, perpetration of violence against children, and interaction with children

Table 2.9: Percentage of parents who discussed non-sensitive and sensitive matters with their children

Table 2.10: Percentage of daughters and sons reporting parental encouragement to exercise own agency, parental perpetration of violence against them, and extent of interaction with parents

Table 2.11: Percentage of daughters and sons reporting that parents had discussed non-sensitive and sensitive matters with them

Table 3.1: Parents' awareness of and exposure to the intervention and regularity of attendance of intervention activities, endline survey

Table 3.2: Adolescents' exposure to the intervention as reported by parents and adolescents, endline survey 
Table 3.3: Perceptions about the programme and reasons for participating

Table 3.4: Extent of exposure to the curriculum and perceptions of parents and adolescents about the usefulness of the curriculum

Table 4.1: Awareness about physical maturation and other SRH matters among participant and non-participant parents at baseline and endline

Table 4.2: Gender role expressed by participant and non-participant parents at baseline and endline

Table 4.3: Attitudes about involving children in decisions affecting their own life expressed by participant and non-participant parents at baseline and endline

Table 4.4: Perceptions about parents' role in communicating non-sensitive and sensitive matters to adolescents expressed by participant and non-participant parents at baseline and endline

Table 4.5: Socialisation practices reported by participant and non-participant parents at baseline and endline

Table 4.6: Parent-child communication: Percentage of participant and non-participant parents who discussed non-sensitive and sensitive matters with their adolescent children at baseline and endline

Table 4.7a: Socialisation experiences reported by adolescent children of participant and non-participant parents at baseline and endline

Table 4.7b: Communication with parents: Percentage of adolescent children of participant and non-participant parents who discussed non-sensitive and sensitive matters with their parents at baseline and endline 


\section{List of Figures}

Figure 4.1: Effects of exposure to the intervention programme on parents' awareness about physical maturation and other SRH matters

Figure 4.2: Effects of exposure to the intervention programme on mothers' attitudes about involving children in decisions affecting their own lives

Figure 4.3: Effects of exposure to the intervention programme on mothers' perceptions about parents' role in communicating sensitive matters to adolescents

Figure 4.4: Self-assessment of relationship with children: Percentage of mothers and fathers who reported in the endline survey a closer relationship with children than prior to participation in the intervention (participants)/a year earlier (non-participants)

Figure 4.5: Self-assessment of communication with children: Percentage of mothers and fathers who reported in the endline survey greater ease in communicating with their adolescent children about SRH matters than prior to participation in the intervention (participants)/a year earlier (non-participants)

Figure 4.6: Effects of parental exposure to the intervention programme on indicators of sons' and daughters' socialisation experiences, as reported by adolescent boys and girls 


\section{Acknowledgements}

This study has benefited immeasurably from the inputs of many. We are extremely grateful to the Ford Foundation for its financial support which made this study possible, and to Vanita Nayak Mukherjee, Programme Officer for her interest in and inputs into this project.

At CEDPA India, several colleagues have supported the project, in both implementation and management. We thank Swati Parmar, Priyanka Mukherjee, Sandeep Ojha and Nancy Mittal for technical advice and support in curriculum design and development, Sanjay Paul and Alpan Sinha in training and capacity building of project functionaries and Prakash Ranjan for project supervision and management.

We are also grateful to the staff of Geeta Mahila Uthan Samiti (GMUS) who were responsible for field implementation of a challenging project, which they did diligently.

At the Population Council, several colleagues have supported us in both the technical and the administrative aspects of this study. We would also like to thank M.A. Jose for ably managing the administrative aspects of the project, Shilpi Rampal for her support with data management, our former colleagues Ravi Prakash and Shagun Sabarwal for their support in preparing instruments, training of interviews and field monitoring of the baseline survey, and Komal Saxena for ably coordinating the printing of the report. We are grateful to Annu Kurien and Komal Saxena for their editorial contributions. We also appreciate the efforts of our investigators who painstakingly collected the data.

Finally, and most importantly, we thank the mothers, fathers and their sons and daughters who took part in our intervention, and who generously gave us their time and shared their views and experiences with us during the course of the baseline and the endline surveys.

Shireen J Jejeebhoy

A. J. Francis Zavier

K. G. Santhya

Rajib Acharya

Santosh Singh

Population Council

Aparajita Gogoi

Vinita Nathani

CEDPA India 


\section{Chapter 1 Introduction}

\section{Introduction and objectives}

Parents are in a unique position to influence their children's health, personal development and transition into adult life (World Health Organization [WHO], 2007). Family-level factors, such as socialisation patterns, the extent to which these are gendered and connectedness and communication between parents and children, influence significantly the nature of young people's transition to adulthood. Globally, there have been only few interventions that have focused on building parenting skills to narrow the schism between parents and children. These interventions aimed to build parental awareness of adolescent health and development, enhance gender-egalitarian socialisation of sons and daughters and enable parents to communicate better with their adolescent children, particularly about sexual and reproductive matters. The notable interventions among these are the Families Matter! Program (FMP), which was designed for implementation in the U.S., but has been adapted for adolescents in rural Kenya as well (see, for example, Vandenhoudt et al., 2010), and Improving the communication between parents and adolescent in reproductive health and HIV/AIDS implemented in Senegal by the Centre for Development and Population Activities (CEDPA) and the Population Council (Diop and Diagne, 2008). Evaluations of these interventions suggest that exposure to the interventions had positive effects on parent-child communication, such as the ability to discuss sensitive matters and the quality of such interaction, and on sexual and reproductive health (SRH) outcomes for children (Vandenhoudt et al, 2010; Diop and Diagne, 2008).

While evidence from India about parent-child interaction and communication is sparse, available studies confirm that socialisation is gendered and hierarchical and that parent-child communication is limited, particularly with regard to sensitive matters such as puberty and the physical changes associated with it, sex, pregnancy and sexually transmitted infections (STIs)/HIV. These studies suggest that parents are not fully informed about SRH matters themselves and that they hold many misperceptions about communicating with their adolescent sons and daughters on these topics, such as fears that this communication would lead their children astray (see for example, Jejeebhoy and Santhya, 2011; Shekhar Ghosh and Panda, 2007; Abraham and Kumar, 1999; Mehra, Savithri and Coutinho, 2002; Alexander et al., 2006; International Institute for Population Sciences [IIPS] and Population Council, 2010). Strong cultural taboos also inhibit parents from discussing sex with their children (Lambert and Wood, 2005).

There is a recognition in India's policies and programmes, as seen in its recent Rashtriya Kishor Swasthya Karyakram (National Adolescent Health Programme), of the need to actively engage parents in enabling their adolescent children to make safe and healthy transitions to adulthood (Ministry of Health and Family Welfare, 2006; 2014). While some skill-building programmes for adolescents have made efforts to expose parents to activities that their children undertake in the course of these programmes (see, for example, the PRACHAR programme and CEDPA's Better Life Options), so far, programmes specifically on parenting have not been implemented, and not a single programme has focused on building parent-child communication or considered parents as the primary focus of the intervention. There is a need, therefore, to implement and test models that would bridge the distance between parents and children, encourage parents to adopt more gender-egalitarian socialisation practices and improve communication between parents and their adolescent children on SRH matters.

With this as the background, the Population Council, in partnership with CEDPA India, initiated an intervention project for parents of adolescents. The project aimed to develop and test a programme to foster closer relationships between parents and their adolescent children. The project was built upon prior research by the Population Council, which indicated that there was a wide schism in communication and interaction between parents and their adolescent children, particularly in the areas of physical maturation and SRH. The research also indicated that parents were both poorly informed about these matters and uncomfortable about discussing them with their children. This project was formulated on the hypothesis that a programme intended to build parenting skills, particularly in the areas of communication and interaction, would enable parents to develop closer 
relationships with their adolescent children and to communicate more effectively with them on various concerns pertaining to their children, particularly those related to growing up and SRH matters, and thereby enable healthier development of adolescents in the long run. The intervention was implemented by CEDPA India and comprised a total of 16 sessions for groups of mothers and, correspondingly, 16 sessions for groups of fathers and 4 joint sessions in which their adolescent children were also invited to participate. The Population Council was responsible for evaluating the feasibility, acceptability and effectiveness of the intervention on parent-child relations and communication.

This report documents the intervention, examines the feasibility of implementing the model and evaluates its effectiveness and acceptability. Specifically, the report assesses the feasibility of implementing the model; it assesses its acceptability as perceived by mothers and fathers of adolescents in the ages of 13-17 years; it evaluates the effectiveness of the model in raising awareness of mothers and of fathers on SRH matters, in changing their attitudes towards socialisation of and communication with their adolescent children and in changing behaviours, notably parent-child communication and socialisation of sons and daughters; and it explores adolescents' own perceptions about the changes brought about in their parents' interaction and communication over the period of the intervention.

\section{Project setting}

The project was implemented in a rural setting in Arrah Block of Bhojpur district in the state of Bihar. The project sites and state were purposively selected. Both the Population Council and CEDPA India had worked extensively in the state to assess the situation of and implement interventions for young people. The selection of the site was also influenced by CEDPA India's ties to the communities and local partners in the study areas.

The state of Bihar represents one of the most backward states economically and socially in India. Bihar has a population of about 104 million and is the second largest state in the country, representing 9 percent of India's population (Office of the Registrar General and Census Commissioner, India, 2013). Although Bihar has a more balanced child sex ratio than the all-India ratio (935 females per 1,000 males in 2011 compared with 918 females per 1,000 males in India as a whole), it lags behind the rest of India in terms of most of the social and health indicators. The literacy rate was 62 percent in 2011 compared with 73 percent nationally. The prevalence of child marriage is higher than in any other state in the country, with 68 percent of currently married women aged 20-24 having been married before the age of 18 years (IIPS, 2010). Moreover, childbearing in adolescence is common; 43 percent of currently married girls aged 15-19 were already mothers and another 13 percent were pregnant at the time of the survey. The maternal mortality ratio in the state (together with the neighbouring state of Jharkhand) far exceeds that reported for the country as a whole-219 per 100,000 births versus 178 per 100,000 births (Office of the Registrar General, India, 2013)-and the utilisation of maternal health services is also limited (IIPS and Macro International, 2008). While evidence on parent-child communication is limited, a qualitative study observes that just half of mothers (14 of 28) and just one father (out of 21) in Bihar had discussed physical changes associated with puberty with their daughter. Similarly, just 14 percent of mothers and 20 percent of fathers had discussed these matters with their son (Jejeebhoy and Santhya, 2011). The Youth in India: Situation and Needs study notes, moreover, that hardly any young women and men reported that they had discussed such matters as reproductive processes or boy-girl relationships with either parent, a finding noted in most other states as well (IIPS and Population Council, 2010).

Bhojpur district, with a population of 2,728,407, contains some 2.6 percent of the population of Bihar. Its sociodemographic characteristics are largely similar to those of the state. The literacy rate among females in the ages of 7 years or above is just 58 percent, the number of economically active women constituted 17 percent and the number of those married in childhood (below age 18 years) constituted 72.8 percent of females aged 20-24. A few key indicators of the study district and Bihar state are presented in Table 1.1. 
Table 1.1: Socio-demographic indicators, Bihar state and Bhojpur district

\begin{tabular}{|c|c|c|}
\hline & Bihar state & Bhojpur district \\
\hline Total population, ${ }^{\mathrm{a}} 2011$ & $104,099,452$ & $2,728,407$ \\
\hline Population aged $13-17,{ }^{b} 2011(\%)$ & 9.9 & 10.4 \\
\hline Female literacy rate (ages 7 or more years), ${ }^{a} 2011(\%)$ & 51.5 & 58.0 \\
\hline Economic activity among women ${ }^{a}(\%)$ & 23.4 & 16.9 \\
\hline Population belonging to scheduled castes and tribes, ${ }^{a} 2011$ (\%) & 17.2 & 16.1 \\
\hline Child sex ratio, 2011 & 935 & 918 \\
\hline Currently married women aged $20-24$ who were married below age 18 years $^{\mathrm{C}}(\%)$ & 68.2 & 72.8 \\
\hline $\begin{array}{l}\text { Currently married women aged } 15-49 \text { practising contraception at the time of the } \\
\text { interview, } 2011-12^{d}(\%)\end{array}$ & 43.0 & 45.4 \\
\hline $\begin{array}{l}\text { Three or more ante-natal check-ups received, women aged } 15-49 \text { who had a live/ } \\
\text { stillbirth in the three years preceding the survey }{ }^{d}(\%)\end{array}$ & 34.2 & 37.2 \\
\hline
\end{tabular}

Source: ${ }^{a}$ Office of the Registrar General and Census Commissioner, India (n.d. a); ${ }^{b}$ Office of the Registrar General and Census Commissioner, India (n.d. b); cIIPS, (2010); ${ }^{d}$ Office of the Registrar General India and Census Commissioner (n.d. c).

Intervention activities were conducted in 13 villages of Arrah block (Bhojpur district, Bihar) that fall under two panchayats (local self-government bodies). The two panchayat areas were selected purposively and represented areas in close proximity to where CEDPA India's local partner had its base. Our evaluation was conducted in all of these villages.

\section{Study design}

The project was based on a pre-evaluation and post-evaluation (pre-post) research design, with panel surveys conducted among mothers and fathers of adolescent boys and girls as well as among adolescent boys and girls themselves. We considered the pre-post design as suitable for this pilot project, because this design would allow us to assess the relevance, acceptability and feasibility of the intervention among parents and adolescents as well as shed light on the intervention's effectiveness in changing parental awareness, attitudes and practices. Besides, there are only few precedents of parenting interventions in the Indian context. Surveys were conducted among parents of 13-17-year-old adolescents prior to (baseline survey) and after the implementation of the intervention (endline survey) in order to evaluate the effects of intervention activities on the knowledge, attitudes and behaviours of the parents. Similarly, baseline and endline surveys were also conducted among 13-17-year-old adolescents themselves prior to and after the implementation of the intervention to evaluate their experiences of socialisation and communication with parents and changes experienced over the course of the intervention.

The baseline survey was conducted from November 2012 to January 2013. Prior to conducting the baseline survey, we conducted a rapid enumeration of households in selected villages. This entailed a listing of each household and the identification of eligible households (those containing an unmarried adolescent boy or girl aged 13-17 and at least one co-residing parent or guardian). All households that contained eligible respondents, that is, adolescents aged 13-17 and co-residing parents, constituted the sampling frame for selecting mothers, fathers, adolescent girls and adolescent boys for the interview. A total of 2,807 households were thus enumerated, and this yielded a total of 895 households containing one or more adolescents aged 13-17 and a co-residing parent. Mothers were interviewed in even-numbered households and fathers in odd-numbered households. We then invited unmarried adolescents aged 13-17 from the households in which a parent was interviewed to take part in the survey. If the household contained more than one adolescent, we selected one (girl or boy) randomly using the Kish table (Kish, 1949) so as to obtain a sample of adolescents more or less equally divided between girls and boys.

The endline survey was conducted from October 2013 to December 2013. For this, we again contacted all those parents and adolescents who had consented, during the baseline survey, to being approached once again to participate in the endline survey that was to be conducted approximately nine months to one year after the 
conclusion of the baseline survey. All baseline survey respondents who had consented were re-contacted for interview at the time of the endline survey; those interviewed for the endline survey thus included those who had gone on to take part in the intervention, and those who had not done so.

\section{Study instruments}

Two questionnaires were developed for the study: a parents' questionnaire administered to mothers of 13-17-yearold adolescents and fathers of 13-17-year-old adolescents; and an adolescent questionnaire administered to girls and boys aged 13-17. Questionnaires were adapted from those used in previous Population Council studies (Acharya et al., 2009; Population Council, 2013).

The baseline survey for parents sought to elicit information on the background characteristics of respondents, their attitudes towards gender and parental responsibilities and their attitudes about parent-child communication with adolescent children, including on SRH issues. It sought information on socialisation practices, awareness about SRH matters and relationships and communication of parents with their children, including communication on SRH matters. The endline and baseline questionnaires were identical, except for an additional module in the endline questionnaire for those who had participated in the intervention. The module contained questions on the respondents' experiences and perceptions about the acceptability and quality of the programme and the extent to which their participation in the programme had influenced socialisation practices and parent-child interaction and communication, especially on sensitive SRH matters.

Instruments for adolescents focused on parent-child interaction and socialisation, and questions were framed to correspond to or parallel the questions posed to the parents. We had also inquired from adolescents in the endline survey whether they had attended any of the joint parent-child sessions.

\section{Response rates}

For the baseline survey, 502 mothers, 393 fathers, 379 daughters and 455 sons were identified and invited for interviews. Of these, 478 mothers, 357 fathers, 362 daughters and 429 sons were interviewed. Response rates were similar among fathers (91 percent) and mothers (95 percent) and similar for daughters and sons (95 percent and 94 percent, respectively). Refusal rates were low for the baseline survey among all sub-groups (2 percent or less). We note that some respondents were unavailable for interviews, because they were not at home even after field teams made three to four visits ( 2 percent to 3 percent).

Table 1.2: Response rate at baseline and reasons for non-response

\begin{tabular}{lcccc}
\hline & Mothers & Fathers & Daughters & Sons \\
\hline Sample identified & 502 & 393 & 379 & 455 \\
Interviewed & 478 & 357 & 362 & 429 \\
Not available at home & 15 & 20 & 9 & 21 \\
Respondent refused & 7 & 7 & 6 & 0 \\
Parent refused & NA & NA & 2 & 1 \\
Partially completed & 0 & 3 & 0 & 1 \\
Incapacitated & 2 & 6 & 0 & 3 \\
Response rate & $\mathbf{9 5 . 2}$ & $\mathbf{9 0 . 8}$ & $\mathbf{9 5 . 2}$ & $\mathbf{9 4 . 3}$ \\
\hline
\end{tabular}

Note: NA: Not applicable. 
A considerable number of baseline respondents, however, were unavailable for the endline survey (Table 1.3), mainly because they had moved away (migrated for work), were visiting their natal homes (mothers) or had moved away for education or after marriage (adolescent daughters). Some were not available even after three to four visits to the household. Refusal rates in the endline survey continued to be low, although these were slightly higher than those for the baseline survey. In the endline survey, 457 mothers, 307 fathers, 322 daughters and 374 sons were re-interviewed, with follow-up rates of 96 percent, 86 percent, 89 percent and 87 percent, respectively.

Table 1.3: Follow-up rates in endline survey and the reasons for loss of sample in the follow-up

\begin{tabular}{lcccc}
\hline & Mothers & Fathers & Daughters & Sons \\
\hline Sample interviewed at baseline & 478 & 357 & 362 & 429 \\
Interviews completed at endline & 457 & 307 & 322 & 374 \\
Not available at home & 7 & 10 & 11 & 10 \\
Respondent refused & 2 & 20 & 2 & 10 \\
Parent refused & 0 & 0 & 0 & 2 \\
Family moved out & 0 & 0 & 2 & 0 \\
Respondent died & 1 & 2 & 0 & 0 \\
Moved out of state/district for marriage, work or education & 9 & 17 & 25 & 33 \\
Partially completed & 1 & 1 & 0 & 0 \\
Incapacitated & 1 & 0 & 0 & 0 \\
Follow-up rate & $\mathbf{9 5 . 6}$ & $\mathbf{8 6 . 0}$ & $\mathbf{8 9 . 0}$ & $\mathbf{8 7 . 2}$ \\
\hline
\end{tabular}

Note: All baseline survey respondents were eligible for interview in the endline survey; only those who had consented to being re-contacted for interview at the time of the endline survey were however approached.

\section{Structure of the report}

The report is divided into five chapters, including this introductory chapter. Chapter 2 presents a profile of the lives of parents and adolescents at the time of the baseline surveys and their socio-demographic characteristics. It sheds light on those aspects of their lives that the intervention aimed to address, such as parents' awareness of $\mathrm{SRH}$ matters, attitudes on gender roles and socialisation of children, communication with children and experiences in interacting and communicating with children, particularly on sensitive topics. Corresponding information from adolescents presents their perspectives on the extent of interaction and communication they had experienced with their parents. Chapter 3 briefly describes the objectives and design of the intervention, its key components, the extent of parents' participation in intervention activities, their experiences and assessment of the intervention programme, particularly their views about the sessions, the quality and acceptability of the programme and other such concerns, and adolescents' own reports of their exposure to the intervention sessions in which parents were invited to bring their adolescent son or daughter. It also highlights challenges faced in implementing the programme. Chapter 4 presents findings from mothers and fathers with regard to the effects of the intervention on their awareness of SRH matters and on their attitudes about gender roles and about informing children about physical maturation and SRH issues. It also assesses the effect of the intervention on socialisation patterns and communication with children as reported by mothers and fathers, on the one hand, and participating parents' sons and daughters, on the other. The final chapter (Chapter 5) summarises the main findings of the study, and highlights lessons learnt for future programme implementation. 


\section{Chapter 2 \\ Profile of the lives of parents and adolescents}

Drawing on data from the baseline survey, this chapter presents a profile of the lives of parents and of their unmarried adolescent sons and daughters (those between 13 and 17 years) of the study villages. We first present the socio-demographic situation of the parents and adolescents. This is followed by a discussion of the extent of awareness of parents themselves on physical maturation and SRH matters. We then present data capturing gender-role attitudes of parents, their perceptions about socialisation practices for sons and daughters, and their perceptions about communicating with their adolescent children. This is followed by data on parents' reports about the socialisation practices that they followed and the reported extent of their communication with their adolescent children. We end with the perspectives of adolescent boys and girls with regard to their socialisation experiences and communication with their parents.

\section{A. Socio-demographic profile of respondents}

Drawing on data from parents of adolescents in the age group 13-17 years, Table 2.1 describes the household and individual characteristics of these parents in the study sites. Findings on household characteristics relating to religion suggest that an overwhelming majority (92 percent of mothers and 95 percent of fathers) were Hindus. Distributions based on caste suggest that 18 per cent of mothers and 24 percent of fathers belonged to scheduled castes and scheduled tribes, 59 percent of mothers and 50 percent of fathers belonged to other backward castes, and 24 percent of mothers and 26 percent of fathers belonged to general castes. We measured household economic status by using a wealth index composed of household asset data on ownership of selected durable goods, including means of transportation and access to a number of amenities. The wealth index was constructed by allocating scores to a household's reported assets or amenities (for details of the scores, see Appendix 1). Index scores, so constructed, ranged from 0 to 58. The household wealth index confirms the considerable poverty of the selected households-the average household scored only 16-17 on the wealth index (of a maximum possible score of 58).

Data in Table 2.1 on individual characteristics of parents indicate that the age profile of mothers and fathers were, on average, 41 and 46 years, respectively. Findings on educational attainment of parents show that just 12 percent and 60 percent of mothers and fathers respectively, had completed eight or more years of schooling, and 3 percent and 35 percent had completed secondary education. Indeed, educational attainment levels differed widely between fathers and mothers-the median number of years of education completed by fathers was nine years, while over half of mothers had never been to school. While almost all fathers were employed or self-employed (92 percent) in the year preceding the interview, just 29 percent of mothers reported paid work experience.

The survey probed the extent of exposure of parents to the mass media (TV, radio and print) by eliciting information about whether or not parents watched television and listened to the radio. It also sought to establish whether those with five or more years of education read newspapers, magazines or books. Findings confirm that not all parents were exposed to the media. Exposure to at least one medium was reported by 44 percent of mothers as compared with 75 percent of fathers.

Drawing on data from adolescents, Table 2.1 presents the socio-demographic characteristics of the sons and daughters of adult respondents. Adolescents were all aged 13-17, with the average age of sons being 14.4 years and that of daughters being 14.5 years. Adolescents were considerably better educated than their parents, and gender differences were negligible in their levels of educational attainment-daughters and sons had completed on average 7 and 8 years of schooling, respectively, and about 82 percent of daughters and 90 percent of sons were in school at the time of the interview. Finally, many daughters and sons were economically active-27 percent and 79 percent, respectively, and had been engaged in any work (paid or unpaid) in the 12 months prior to the interview. This was almost entirely for unpaid work, and only less than 1 percent had been engaged in paid work. 
Table 2.1: Selected household characteristics and individual characteristics of parents (mothers and fathers) of 13-17-year-old adolescents, and of the adolescents (daughters and sons aged 13-17), baseline survey

\begin{tabular}{|c|c|c|}
\hline & Mothers $(\mathrm{N}=\mathbf{4 7 8})$ & Fathers $(\mathrm{N}=357)$ \\
\hline \multicolumn{3}{|l|}{ Household characteristics } \\
\hline \multicolumn{3}{|l|}{ Religion (\%) } \\
\hline Hindu & 92.1 & 95.0 \\
\hline \multicolumn{3}{|l|}{ Caste (\%) } \\
\hline SC/ST & 17.6 & 23.5 \\
\hline OBC & 58.6 & 50.4 \\
\hline General & 23.8 & 26.1 \\
\hline Standard of living index (ranges 0 to 58) [mean] & 17.1 & 15.9 \\
\hline \multicolumn{3}{|l|}{ Individual characteristics of parents } \\
\hline Mean age & 40.5 & 46.4 \\
\hline \multicolumn{3}{|l|}{ Education (\%) } \\
\hline No education & 60.0 & 19.9 \\
\hline $1-7$ years & 28.5 & 20.4 \\
\hline $8-9$ years & 8.6 & 25.2 \\
\hline 10 or more years & 2.9 & 34.5 \\
\hline Median years of education & NC & 9 \\
\hline \multicolumn{3}{|l|}{ Work (\%) } \\
\hline Engaged in paid work in the last year & 28.9 & 92.1 \\
\hline \multicolumn{3}{|l|}{ Mass media exposure (\%) } \\
\hline \multirow[t]{2}{*}{ Any media (TV, radio, print) exposure } & 44.2 & 75.4 \\
\hline & Daughters $(\mathrm{N}=362)$ & Sons $(N=429)$ \\
\hline
\end{tabular}

Individual characteristics of adolescents

Age (\%)

$13-14$

15-17

Mean age

Education (\%)

No education

1-7 years

8-9 years

10-12 years

\section{Work (\%)}

Engaged in unpaid work in the last year

Mass media exposure (\%) 
As in education, adolescents had considerably more exposure to the media (TV, radio and print) than their parents had. Thus, 77 percent of daughters and 91 percent of sons reported regular media exposure, which was considerably more than their mothers and fathers.

\section{B. Parental awareness about physical maturation and SRH matters}

Previous research in India has shown that aside from negative attitudes about the provision of SRH information to adolescents, parents themselves are not fully informed about these matters. Indeed, even parents who favour the provision of SRH information to adolescents are inhibited by their own lack of understanding about these issues (Jejeebhoy and Santhya, 2011). Our survey explored parental awareness about physical maturation issues as well as awareness about SRH matters more generally. In this section, we describe baseline findings relating to these issues for parents.

With regard to physical maturation issues, we explored parental awareness of the physical and behavioural changes associated with adolescence. We asked parents whether they agreed or disagreed with the following statements: nocturnal emission is common for a boy who has entered puberty; it is all right for a girl to bathe during her periods; after a girl reaches puberty, she becomes interested in boys; after a boy reaches puberty, he becomes interested in girls; after a girl reaches puberty, she takes more interest in her personal appearance, for example, in her looks and dress; after a boy reaches puberty, he takes more interest in his personal appearance, for example, in his looks and dress; after a girl reaches puberty, she becomes more defiant and moody; and after a boy reaches puberty, he becomes more defiant and moody. The respondent was given a score of one for each statement with which she/he agreed and zero if she/he did not agree. The scores were added to create an index of awareness on physical maturation issues, the value of which ranged from zero, which indicated no awareness, to eight, which suggested high levels of awareness. Findings, presented in Table 2.2, suggest that while, on the whole, parents were correctly informed about six of the eight issues probed, gender disparities were observed in awareness on several matters (mean scores of 6.3 and 6.0 among fathers and mothers, respectively). Among mothers, for example, 48 percent were aware about nocturnal emission compared with 81 percent of fathers; in contrast, 63 percent of fathers believed that it is acceptable for a girl to bathe during menstruation compared with almost all mothers (95 percent). Fathers appeared more likely than mothers to recognize that opposite-sex attractions may develop during adolescence among boys ( 90 percent among fathers versus 77 percent among mothers). Similarly, existence of opposite-sex attraction among girls was acknowledged by 85 percent of fathers and 72 percent of mothers.

With regard to child marriage, we assessed parents' awareness of the legal minimum age for marriage for girls and boys. Awareness was far from universal-only 63 percent of mothers and 72 percent of fathers were aware that 18 years is the legal minimum age for marriage for girls, and even fewer parents ( 23 percent of mothers and 32 percent of fathers) were aware that 21 is the legal minimum age for marriage for boys.

In order to measure parents' awareness of sex and pregnancy, two statements were provided and parents were asked whether these were correct: a woman can get pregnant the first time she engages in sexual relations; and a woman is most likely to get pregnant if she has sex when she is in mid-cycle, that is, midway between two successive menstrual periods. Findings, presented in Table 2.2, show that parents who were aware about these matters were few. Indeed, just 38 percent of mothers and 40 percent of fathers were aware that a woman can become pregnant the first time she engages in sexual relations, 73 percent each of mothers and fathers were aware that the likelihood of becoming pregnant is greatest if a woman engages in sexual relations mid-cycle and only 31 percent each of mothers and fathers were aware of both these facts.

With regard to contraception, we explored both general awareness of contraceptive methods (whether parents had heard of various methods of contraception) and specific knowledge of four non-terminal methods of contraception. To elicit information on the latter, parents were asked the following: how often should oral contraceptive pills be taken? (daily or weekly); how many times can one male condom be used?(once); where is the intrauterine contraceptive device (IUCD) inserted? (uterus); and within how many hours following unprotected sex should emergency contraceptives pills (ECPs) be taken to be effective in preventing pregnancy? (72 hours). In estimating extent of condom awareness, we also probed commonly held misperceptions that condoms reduce sexual pleasure and that they can disappear inside the woman's body. While all parents had heard about at least one non-terminal 
Table 2.2: Percentage of parents reporting awareness about various aspects of physical maturation and other SRH matters, baseline survey

\begin{tabular}{|c|c|c|}
\hline & $\begin{array}{l}\text { Mothers } \\
(\mathrm{N}=\mathbf{4 7 8})\end{array}$ & $\begin{array}{l}\text { Fathers } \\
(\mathrm{N}=357)\end{array}$ \\
\hline \multicolumn{3}{|l|}{ Physical maturation } \\
\hline Nocturnal emission is common for a boy who has entered puberty & 48.2 & 80.7 \\
\hline It is all right for a girl to bathe during her periods & 95.3 & 63.4 \\
\hline After a girl reaches puberty, she becomes interested in boys & 71.5 & 85.2 \\
\hline After a boy reaches puberty, he becomes interested in girls & 77.0 & 90.0 \\
\hline After a girl reaches puberty, she takes more interest in her personal appearance, e.g., looks, dress & 98.1 & 96.0 \\
\hline After a boy reaches puberty, he takes more interest in his personal appearance, e.g., looks, dress & 98.7 & 98.1 \\
\hline After a girl reaches puberty, she becomes more defiant and moody & 42.1 & 45.6 \\
\hline After a boy reaches puberty, he becomes more defiant and moody & 64.5 & 69.0 \\
\hline $\begin{array}{l}\text { Index of awareness of physical maturation issues [mean] (Range } 0 \text { to 8; Cronbach's alpha; } \\
\text { mother }=0.60 \text {, father }=0.60 \text { ) }\end{array}$ & 6.0 & 6.3 \\
\hline \multicolumn{3}{|l|}{ Legal minimum age for marriage } \\
\hline For boys & 23.2 & 32.3 \\
\hline For girls & 62.5 & 71.6 \\
\hline \multicolumn{3}{|l|}{ Pregnancy } \\
\hline Aware that a woman can get pregnant the very first time she has intercourse & 37.6 & 39.6 \\
\hline Aware that a woman is most likely to become pregnant if she has intercourse midcycle & 73.2 & 73.1 \\
\hline $\begin{array}{l}\text { Aware that a woman can get pregnant the very first time she has intercourse and that a woman is } \\
\text { most likely to become pregnant if she has intercourse midcycle }\end{array}$ & 31.0 & 30.8 \\
\hline \multicolumn{3}{|l|}{ Contraception } \\
\hline Had heard of at least one modern non-terminal contraceptive method & 96.9 & 92.7 \\
\hline Oral pills & 95.0 & 79.4 \\
\hline ECPs & 10.6 & 43.5 \\
\hline Condoms & 81.7 & 87.7 \\
\hline IUCDs & 89.0 & 53.8 \\
\hline Injectables & 27.9 & 6.0 \\
\hline Other methods (implant or vaginal contraceptive tablets) & 0.1 & 1.5 \\
\hline \multicolumn{3}{|l|}{ In-depth awareness of contraceptives } \\
\hline In-depth awareness of oral pills & 66.5 & 27.9 \\
\hline In-depth awareness of ECPs & 4.5 & 7.9 \\
\hline In-depth awareness of condoms & 54.5 & 64.8 \\
\hline In-depth awareness of IUCDs & 53.2 & 17.6 \\
\hline In-depth awareness of at least one method (oral pills, ECPs, condom, IUCDs) & 77.1 & 69.2 \\
\hline $\begin{array}{l}\text { Dispelled misconceptions that condoms reduce sexual pleasure or slip off the man } \\
\text { and disappear inside the woman's body }\end{array}$ & 8.8 & 16.3 \\
\hline \multicolumn{3}{|l|}{ HIV/AIDS and symptoms of STIs } \\
\hline Heard of HIV/AIDS & 43.4 & 79.9 \\
\hline Have comprehensive knowledge of HIV/AIDS & 10.7 & 23.6 \\
\hline Heard of infections that people get from sexual contacts other than HIV/AIDS & 24.6 & 25.7 \\
\hline
\end{tabular}


method of contraception (93 percent of fathers and 97 percent of mothers), gender differences were apparent. Mothers were more likely than fathers to have heard about oral contraceptive pills, IUCDs and injectables, and fathers were more likely than mothers to have heard about condoms and emergency contraception. Correct specific knowledge of various non-terminal methods was, however, limited among both mothers and fathers. Indeed, about 77 percent of mothers and 69 percent of fathers were aware, in-depth, about at least one method of contraception (typically condoms among fathers and oral contraceptive pills among mothers). Moreover, very few parents-9 percent of mothers and 16 percent of fathers-had dispelled common misperceptions about condoms.

Awareness of STIs and HIV was similarly limited, particularly among mothers (Table 2.2). Thus, among mothers, only 43 percent had heard of HIV, and even fewer mothers-only 25 percent-had heard of other STIs. While fathers were better informed, not all of them had heard of HIV ( 80 percent of fathers had heard of HIV) or were aware of infections other than HIV that are spread by sexual contact (only 26 percent of fathers were aware). Worse still, just 11 percent and 24 percent of mothers and fathers, respectively, reported comprehensive awareness of HIV/AIDS (that is, they were aware of the protective nature of condom use and single-partner relations and did not hold misconceptions about HIV infection, such as transmission of HIV through mosquito bites, sharing of food or hugging and that HIVinfected people can be identified merely by their appearance).

\section{Parental gender-role attitudes and their perceptions about socialisation practices for adolescents and about communication with adolescents}

The baseline survey explored several dimensions of parental attitudes and perceptions about gender roles, socialisation practices for and communication with adolescents. These included parents' gender-role attitudes, their perceptions of gender-equitable roles in childrearing, parent-child communication and the norms they hold about communication with children about SRH matters.

\section{Gender-role attitudes}

In order to probe parents' attitudes to gender roles, we asked respondents to agree or disagree with five statements that we had presented to them. These statements were: it is acceptable for a man to hit his wife if she does not have sex with him; a man should have the final word about decisions related to household matters; bathing and feeding children are only the mother's responsibility; a married woman need not seek her husband's permission if she wishes to visit her natal family; and a woman should obtain her husband's permission for most things.

Findings based on these statements are presented in Table 2.3, and they suggest a mixed scenario. Almost all mothers (95 percent) and fathers (92 percent) reported that it is unacceptable for a man to beat his wife if she refuses to have sex with him. Somewhat fewer- 65 percent of mothers and 56 percent of fathers-did not believe that a man should have the final word about household decisions. The remaining three statements elicited egalitarian responses from a few respondents only, and, surprisingly, fewer mothers than fathers reported egalitarian attitudes on these matters. Indeed, just 11 percent of mothers and 38 percent of fathers believed that childcare was the father's responsibility as well as that of the mother's, only 6 percent of mothers and 14 percent of fathers, maintained that a married woman need not obtain her husband's permission for most things, and only 7 percent

Table 2.3: Percentage of parents reporting egalitarian gender-role attitudes

Mothers $(\mathrm{N}=\mathbf{4 7 8})$

Fathers $(\mathrm{N}=357)$

Attitudes about gender roles (Percent reporting egalitarian attitudes on each item)

It is okay for a man to hit his wife if she won't have sex with him (disagree)

A man should have the final word about decisions related to household matters (disagree)

Bathing and feeding young children are the mother's responsibility (disagree)

A married woman need not seek her husband's permission to visit her parents' home (agree)

A woman should obtain her husband's permission for most things (disagree)

Any three of the above five situations
95.5

92.2

64.9

56.0

10.7

38.1

6.7

6.1

13.6

15.3 
of mothers and 10 percent of fathers considered it acceptable for a woman to visit her parents without obtaining permission from her husband. A summary measure of gender-role attitudes reflected the percentage of parents who reported three or more egalitarian attitudes (of a maximum of five). Using this measure, we found that very few parents, particularly mothers, expressed egalitarian attitudes: 37 percent of fathers and just 15 percent of mothers.

\section{Attitudes about involving children in decisions affecting their own lives}

Attitudes about children's involvement in decisions affecting their own lives were captured by four questions that probed parents' perceptions about the right of sons and daughters to exercise agency in marriage-related decisions, such as decisions about when to marry and whom to marry. A summary indicator of parental attitudes about children's decision-making roles is reflected in the responses of parents who agree that children should be involved. Findings, presented in Table 2.4, suggest that mothers and fathers held similar attitudes and were likely to agree that boys should have the right to be involved in marriage-related decisions more than girls.

Table 2.4: Percentage of parents perceiving that girls and boys should have a say in marriage-related decisions

\begin{tabular}{lcc}
\hline & Mothers (N=478) & Fathers (N=357) \\
\hline Attitudes about involving children in decisions affecting their own lives (Percent & & \\
reporting attitudes approving children's involvement in marriage-related decisions) & 84.7 & 85.1 \\
It is all right for boys to have a say in the choice of their marriage partner (agree) & 84.3 & 77.6 \\
It is all right for boys to have a say in when they want to marry (agree) & 67.6 & 67.6 \\
It is all right for girls to have a say in the choice of their marriage partner (agree) & 58.8 \\
It is alright for girls to have a say in when they want to marry (agree) & &
\end{tabular}

\section{Attitudes about parents' responsibilities about informing children about non-sensitive matters (money, savings) and sensitive matters (physical maturation and SRH)}

In order to assess parental perceptions about the need to inform adolescents about both non-sensitive and sensitive matters, we asked parents about whether sons and daughters should be informed about money matters, on the one hand, and physical maturation, boy-girl attraction, pregnancy and contraception, on the other, and if so, when they should be informed (before puberty, in adolescence, or around the time of marriage or later). We present in Table 2.5 percentages that reflect the numbers of mothers and fathers who reported that physical maturation matters should be discussed with adolescents before puberty and that matters of money and savings, the attraction between boys and girls, menstruation or nocturnal emission, how pregnancy happens and contraception should be discussed with adolescents during adolescence and before marriage. The baseline survey captured these perceptions held by mothers with regard to their daughter and/or their son and fathers with regard to their daughter and/or their son. Two summary indexes were created from responses that reflected perceptions about communication on five sexual and reproductive matters. The indexes represented the total number of matters on which parents agreed that daughters and sons must be informed during adolescence or before puberty (shown in Table 2.5).

Findings stress that while almost all parents agreed that adolescents must be informed about money matters, far fewer believed that they should be informed about any matter relating to physical maturation, pregnancy or contraception. Thus, about 54 percent each of mothers and fathers believed that daughters should be aware of boy-girl attraction during adolescence, and 60 percent of mothers and 62 percent of fathers believed this was applicable to sons as well. Far fewer parents-more fathers than mothers-believed that daughters and sons should be informed about physical maturation matters, menstruation/nocturnal emission, pregnancy and contraception during adolescence. Indeed, among mothers, just 6 percent held that daughters should be informed about contraception during adolescence and 10 percent believed that sons should be similarly informed, while more fathers held this opinion with regard to their daughters (24 percent) and sons (32 percent). 
Table 2.5: Percentage of parents agreeing that daughters and sons should be given information on various matters

Mothers $(\mathrm{N}=478) \quad$ Fathers $(\mathrm{N}=357)$

\section{Daughters should be given information on:}

Money matters, e.g., spending and saving or family economic situation

(before puberty, during adolescence)

99.9

93.1

Attraction between boys and girls (before puberty or during adolescence)

53.9

Physical maturation matters, such as breast development, pubic hair growth

(before puberty)

13.6

21.8

Menstruation (before puberty)

17.9

How pregnancy happens/sexual relationships between men and women

(during adolescence)

11.7

Contraception (during adolescence)

Index of attitudes about the provision of information on physical maturation and

SRH to adolescents (Range 0 to 5 ; Cronbach's alpha Mother $=0.54$, Father $=0.63$ )

\section{Sons should be given information on:}

Money matters, e.g., spending and saving or family economic situation

(before puberty, during adolescence)

99.6

98.7

Attraction between boys and girls (before puberty or during adolescence)

59.5

Bodily changes during puberty, such as voice change, pubic hair growth, facial hair

growth (before puberty)

12.0

16.8

Nocturnal emission (before puberty)

6.4

8.6

How pregnancy happens/sexual relationships between men and women

(during adolescence before marriage)

11.7

36.1

Contraception (during adolescence before marriage)

Index of attitudes about the provision of information on physical maturation and

SRH to adolescents (Range 0 to 5 ; Cronbach's alpha Mother $=0.58$, Father $=0.66$ )

1.0

\section{Norms about parent-child communication on sensitive matters}

Available evidence has noted that the key reason parents cite for avoiding discussions on SRH matters with children is that it is culturally inappropriate. They also feel that discussing such matters will lead children "to take a wrong path" or "go astray" (Jejeebhoy and Santhya, 2011). Findings on the extent to which parents in our sample adhered to these norms are presented in Table 2.6 and reiterate that almost all parents-99 percent of mothers and 93 percent of fathers-believed that it was culturally unacceptable to discuss SRH matters with adolescents. Almost one-quarter of mothers and two-fifths of fathers believed that informing adolescents about these matters would lead them astray.

Table 2.6: Percentage of parents reporting adherence to traditional norms on parent-child communication about SRH matters

Mothers $(\mathrm{N}=478) \quad$ Fathers $(\mathrm{N}=357)$

Parents in the village believe it is culturally unacceptable to talk about

$\mathrm{SRH}$ issues with their children

99.2

93.4

If parents inform children about SRH matters,

children will go astray

22.7

39.6 


\section{Perceptions about parental and adolescent shyness about discussing SRH matters}

There is evidence that parents and adolescents alike are shy or uncomfortable about talking to each other about SRH matters (Jejeebhoy and Santhya, 2011). To explore the extent to which parents agreed with these perceptions, we asked them whether they believed that parents and adolescents in their village feel shy about communicating on these matters. Findings on these perceptions are presented in Table 2.7 and suggest that this perception is almost universally held. Indeed, about 97 percent each of mothers and fathers believed that parents in the village are uncomfortable about talking to their children about SRH matters, and 99 percent each believed that children are equally shy about approaching their parents for information on these matters.

Table 2.7 Percentage of parents reporting parental and adolescent shyness about parent-child communication about SRH matters

Mothers $(\mathrm{N}=478)$ Fathers $(\mathrm{N}=357)$

\begin{tabular}{lll}
\hline Parents in the village are shy about talking about & \\
SRH issues with their children & 97.4 & 96.8 \\
$\begin{array}{l}\text { Children in the village are shy about talking to } \\
\text { their parents about SRH issues }\end{array}$ & 98.6 & 99.2 \\
\hline
\end{tabular}

\section{Parents'socialisation practices and communication with adolescents}

As seen in other studies (Abraham and Kumar, 1999; Mehra, Savithri and Coutinho, 2001; Alexander et al., 2006; Shekhar, Ghosh and Panda, 2007; IIPS and Population Council, 2010; Jejeebhoy and Santhya, 2011), findings from the baseline survey reiterate that the socialisation of children is hierarchical and communication between parents and adolescent children rarely touches upon personal matters. Several dimensions of parental socialisation of and communication with their sons and daughters were explored in the baseline survey, and these are described in this section.

\section{Socialisation practices}

We measured socialisation practices in three ways: whether parents permitted their sons and daughters to exercise agency in their everyday life; whether they disciplined their children by using corporal punishment; and whether they regularly interacted with their sons and daughters. Findings are presented in Table 2.8.

In order to understand the extent to which parents enabled adolescents to exercise agency in their everyday life, we asked parents whether they permitted their daughters and sons to make decisions about when to meet their friends and what clothes to buy for themselves and whether they permitted their daughters or sons go out alone to a shop or market, a religious place or to a friend's home. A summary measure reflected the percentage of parents who permitted their children agency on all three matters. This measure revealed wide gender disparities in parental responses in permitting their sons to exercise agency as opposed to their daughters. While 85 percent of mothers and 81 percent of fathers permitted the sons to take decisions about when to meet their friends, just 63 percent of mothers and 51 percent of fathers permitted their daughters to do so. While 99 percent of mothers and 95 percent of fathers permitted their son to go out on their own, just 64 percent of mothers and 41 percent of fathers permitted their daughter to do so. With regard to independent decisions on the purchase of clothes, fathers were more permissive than mothers, but, even so, both mothers and fathers were more likely to permit their son (68 percent and 84 percent, respectively) to make decisions about what clothes to buy for himself than they were to permit their daughter to do so (50 percent and 64 percent, respectively). On the whole, 60 percent of mothers and 69 percent of fathers socialised their sons to exercise agency in all three matters, and just 29 percent of mothers and 25 percent of fathers socialised their daughters to exercise the same agency.

It was clear, moreover, that relations between parents and children were largely authoritarian, with parents using violence to discipline children. Fathers were far more likely to have used violence to discipline their sons (41 percent) than their daughters (13 percent). Among mothers, disparities were narrower, with 45 percent reporting having beaten their son and 38 percent reporting having beaten their daughter in the six months preceding the interview. 
The survey also explored the interaction of mothers and fathers with their children through questions that captured their interaction within the home (whether they had spent time on a regular basis, in the month preceding the interview, conversing or joking with their children) and outside the home (whether they had spent time "doing something fun" with their children or had taken them on an outing, such as to a mela, festival or film in the six months preceding the interview). As seen in Table 2.8, most mothers and fathers had spent time talking to or joking with their daughters ( 89 percent and 82 percent, respectively) and sons ( 84 percent and 87 percent, respectively) in the month preceding the interview. In contrast, few parents did something "fun" with or took their children on an outing in the six months preceding the interview, and wide gender disparities were evident. Mothers were more likely than fathers to have done something "fun" with their sons and daughters or to have taken them on an outing; even so, mothers were far more likely to have interacted with their daughter than their son for a recreational activity (26 percent with daughter versus 15 percent with son). Fathers were slightly more likely to have interacted with their son for a recreational activity than with their daughter (11 percent with son versus 7 with daughter).

Table 2.8: Percentage of parents reporting encouragement of children's agency, perpetration of violence against children, and interaction with children

\begin{tabular}{|c|c|c|c|c|}
\hline & \multicolumn{2}{|c|}{ Mothers } & \multicolumn{2}{|c|}{ Fathers } \\
\hline & Daughter & Son & Daughter & Son \\
\hline Number of parents with daughters and sons ${ }^{1}$ & 284 & 312 & 176 & 249 \\
\hline \multicolumn{5}{|l|}{ Encouragement of children's agency } \\
\hline Decisions about when to meet friends & 62.5 & 84.8 & 50.5 & 81.1 \\
\hline Freedom to go out alone to a nearby shop, a religious place or a friend's home & 63.7 & 98.7 & 41.1 & 95.1 \\
\hline Decisions about what clothes to buy for themselves & 49.5 & 68.2 & 63.8 & 84.1 \\
\hline Encourages children to exercise agency in all three above matters & 29.1 & 60.3 & 24.6 & 68.9 \\
\hline \multicolumn{5}{|l|}{ Perpetration of violence against children } \\
\hline Had beaten/slapped their children in the past six months & 38.2 & 44.8 & 13.4 & 40.5 \\
\hline \multicolumn{5}{|l|}{ Interaction with children } \\
\hline In the past month, spent time regularly talking/joking with their children & 88.8 & 84.4 & 81.7 & 87.1 \\
\hline In the past six months, did something "fun"/took their children on outing & 25.5 & 15.1 & 6.7 & 10.6 \\
\hline
\end{tabular}

Note: ${ }^{1} \mathrm{~A}$ total of 118 mothers and 68 fathers had both a son and a daughter aged $13-17$ and reported on both.

\section{Parent-child communication}

Communication with children was measured in terms of communication on both everyday matters and SRH matters. With regard to parent-child communication on non-sensitive matters, the survey inquired of parents whether they had discussed family problems or money matters with their son or daughter. As shown in Table 2.9, mothers were more likely than fathers to discuss household problems and money matters with both their son and their daughter (89 percent with son and 82 percent with daughter compared with 63 percent with son and 58 percent with daughter by fathers).

We assessed the extent of parent-child communication on sensitive matters by eliciting information on whether they ever discussed such matters as nocturnal emission (for boys), menstruation (for girls), how pregnancy occurs, contraception and HIV/AIDS. Given the limited communication on non-sensitive matters, it is no surprise that, in general, sensitive topics, such as physical maturation, reproduction and contraception, were rarely discussed by either parent. Hardly any parent, for instance, had discussed nocturnal emission with sons, or pregnancy and contraception (0-1 percent), or HIV/AIDS-related issues (2-6 percent) with their son or daughter. The only exception was that almost two-thirds of mothers (65 percent) reported discussing menstrual matters with their daughter. However, the content of this discussion was overwhelmingly related to the dos and don'ts of menstruation, with more than three-quarters ( 77 percent) instructing girls about the "cloth" to wear during menstrual periods and 12 percent instructing them not to visit a temple or enter the kitchen during their periods (not shown in table). 
Table 2.9: Percentage of parents who discussed non-sensitive and sensitive matters with their children

\begin{tabular}{lcccc}
\hline & \multicolumn{2}{c}{ Mothers } & \multicolumn{2}{c}{ Fathers } \\
\cline { 2 - 5 } & Daughter & Son & Daughter & Son \\
\hline Number of parents with daughters and sons ${ }^{1}$ & $\mathbf{2 8 4}$ & $\mathbf{3 1 2}$ & $\mathbf{1 7 6}$ & $\mathbf{2 4 9}$ \\
Non-sensitive matters & & & & \\
Any problems faced in the family or about money matters & 82.3 & 89.1 & 58.4 & 62.6 \\
Sensitive matters & & & & \\
Nocturnal emission (for boys)/Menstruation (for girls) & 65.4 & 0.0 & 0.0 & 1.3 \\
How pregnancy occurs & 1.1 & 0.0 & 0.0 & 0.6 \\
Contraception & 0.4 & 0.0 & 0.0 & 0.6 \\
HIV/AIDS & 5.7 & 3.4 & 1.6 & 3.4 \\
\hline
\end{tabular}

Note: ${ }^{1} \mathrm{~A}$ total of 118 mothers and 68 fathers had both a son and a daughter aged 13-17 and reported on both.

\section{E. Adolescents' perspectives about interaction and communication with parents}

Our survey also inquired from adolescents themselves about their socialisation experiences and extent of communication with their parents, using questions that by and large paralleled those posed to parents. Results by and large corroborate the reports of mothers and fathers.

\section{Socialisation experiences}

As with parents, we measured socialisation experiences in three ways: whether adolescents were permitted to exercise agency in such matters as going alone to a shop, a place of worship or a friend's home; whether they were disciplined by a parent using corporal punishment; and whether their parents had spent time interacting with them within the home and outside it. Findings are presented in Table 2.10.

More sons than daughters were permitted to go out to a shop, place of worship or a friend's home. While almost all sons (97 percent), for example, reported that their parents permitted them to visit these places unescorted, 73 percent and 76 percent of daughters reported that they had the same freedom from their fathers and mothers, respectively. It was clear moreover that relations between parents and children were largely authoritarian, with parents using violence to discipline children. About half of the sons reported that they had been slapped or beaten by their mother ( 50 percent) or father ( 46 percent) in the six months preceding the interview. In contrast, among daughters, one third (33 percent) reported that their mother had beaten or slapped them, and 10 percent reported that their father had done so.

The survey also explored adolescents' responses about whether their mother and father had interacted with them. They were presented with questions that captured their interaction within the home (whether their parents had spent time on a regular basis, in the month preceding the interview, conversing or joking with them) and outside the home (whether their parents had spent time "doing something fun" with them, such as taking them on an outing, mela, festival or film, in the six months preceding the interview). Table 2.10 shows that reported interaction with mothers far exceeded interaction with fathers, particularly for daughters. While 88 percent of sons and 91 percent of daughters reported that their mother had spent time talking to or joking with them in the month preceding the interview, 80 percent of sons and just 42 percent of daughters reported that their father had done so. In contrast, just 8 percent of sons reported that their mother had done something "fun" with them or had taken them on an outing in the six months preceding the interview, with a corresponding 9 percent reporting this with their father. Among daughters, 12 percent reported that their father had done something fun with them or had taken them on an outing six months preceding the interview and 27 percent reported that their mother had done so, reiterating the closer relationship between daughters but not sons and their mothers, and the relatively more distant relationship between fathers and children. 
Table 2.10: Percentage of daughters and sons reporting parental encouragement to exercise own agency, parental perpetration of violence against them, and extent of interaction with parents

\begin{tabular}{|c|c|c|c|c|}
\hline & \multicolumn{2}{|c|}{ Daughters } & \multicolumn{2}{|c|}{ Sons } \\
\hline & Mother & Father & Mother & Father \\
\hline Number of adolescents with surviving and co-residing parents & 361 & 312 & 417 & 396 \\
\hline \multicolumn{5}{|l|}{ Encouragement to exercise agency } \\
\hline Freedom to go out alone to a nearby shop, a religious place or a friend's home & 76.2 & 73.2 & 96.8 & 96.8 \\
\hline \multicolumn{5}{|l|}{ Perpetration of violence against children } \\
\hline Had beaten/slapped children in the past six months & 32.8 & 9.5 & 50.4 & 46.2 \\
\hline \multicolumn{5}{|l|}{ Interaction with children } \\
\hline In the past month, spent time regularly talking/joking with children & 90.6 & 41.6 & 88.3 & 79.7 \\
\hline In the past six months, did something "fun"/took children on outing & 27.0 & 11.6 & 8.3 & 8.9 \\
\hline
\end{tabular}

Adolescents' reports about the extent of their communication with their parents were measured in terms of their communication with parents on both everyday matters and sensitive matters relating to physical maturation and SRH. Findings, reported in Table 2.11, by and large, corroborate their parents' reports of limited communication. With regard to family matters or family problems, three in five sons reported that their mother (62 percent) or father (61 percent) had discussed these matters with them. Although nearly the same proportion of daughters reported that their father had discussed family matters and problems (59 percent), 84 percent of them reported that their mother had discussed these matters with them. Finally, adolescents corroborated that hardly any parent had discussed most matters relating to physical maturation and SRH with them. Indeed, less than 1 percent reported that a parent had discussed pregnancy or contraception with them, 0-4 percent reported that a parent had discussed HIV/AIDs with them, and 0-2 percent of sons reported that a parent had discussed nocturnal emission with them. As in parents' reports, while not a single daughter reported that her father had discussed menstruation with her, 85 percent reported that their mother had done so. As noted by mothers, the content of the discussion (not presented in table) focused overwhelmingly on the mechanics and dos and don'ts of menstruation.

Table 2.11: Percentage of daughters and sons reporting that parents had discussed non-sensitive and sensitive matters with them

\begin{tabular}{|c|c|c|c|c|}
\hline & \multicolumn{2}{|c|}{ Daughters } & \multicolumn{2}{|c|}{ Sons } \\
\hline & Mother & Father & Mother & Father \\
\hline \multicolumn{5}{|l|}{ Non-sensitive matters } \\
\hline Number of adolescents aged 13-17 with surviving and co-residing parents & 361 & 312 & 417 & 396 \\
\hline Any problems faced in the family or about money matters & 84.3 & 59.1 & 62.3 & 60.8 \\
\hline \multicolumn{5}{|l|}{ Sensitive matters } \\
\hline Number of adolescents aged $15-17$ with surviving and co-residing parents & 166 & 137 & 173 & 159 \\
\hline Nocturnal emission (for boys)/Menstruation (for girls) & 84.7 & 0.0 & 1.5 & 0.3 \\
\hline How pregnancy occurs & 0.7 & 0.0 & 0.0 & 0.3 \\
\hline Contraception & 0.4 & 0.0 & 0.0 & 0.3 \\
\hline HIV/AIDS & 3.6 & 3.7 & 0.0 & 2.1 \\
\hline
\end{tabular}




\section{Summary}

In summary, findings highlight that parents in study settings were poorly educated and economically disadvantaged. Three-fifths of mothers had never been to school, and fathers had, on average, just 7 years of schooling. Children were, in contrast, far better educated, with daughters and sons having attained, by the time of the interview, seven and eight years of education, respectively, and many pursuing their education at the time of the interview. Although many parents believed that children should be informed about SRH matters while in adolescence, many obstacles inhibited them from informing their children about these matters. Obstacles included, first, a strong adherence to traditional norms suggesting that it is culturally inappropriate for parents to discuss these matters with their children, and a deep concern that discussing these matters with a child would encourage the child to engage in sexual relations. Second, parents' feelings of discomfort and shyness about talking about these matters with their adolescent children along with their perceptions that their children too would be shy to approach their parents on these matters posed another obstacle. Lastly, parents' own lack of awareness about many matters created obstacles to communication, for example, lack of awareness of whether a woman can become pregnant the first time she engages in sex, how various contraceptive methods are used and how HIV is transmitted and can be prevented.

Socialisation practices were relatively authoritarian as described by both parents and adolescents. Parents' reports highlight that considerable proportions of parents did not encourage their sons and daughters to exercise agency in everyday matters, such as meeting friends, deciding what clothes to buy for themselves and going out alone to a shop or market, a religious place or to a friend's home. Daughters were particularly restricted in exercising agency. Many parents had used violence to discipline their sons and daughters in the six months preceding the interview (while one in eight fathers reported beating their daughters, about two in five fathers reported beating their sons, and two in five mothers reported beating their sons and daughters). Finally, although the majority of parents had spent time conversing and joking with their children on a regular basis in the month preceding the interview, relatively few fathers had so interacted with their daughters in the month preceding the interview. Adolescents' reports reiterate that permission to go out alone was restricted, particularly for daughters, that violence was often used as a means of discipline, particularly for sons, and while interaction within the home was quite common, few sons or daughters had gone out with or done something "fun" with a parent.

Communication with children was limited as reported by both parents and adolescents. Indeed, communication was far from universal even about family matters. It was particularly limited with regard to SRH matters. Reports of both parents and adolescents highlight that hardly any mother or father had discussed how pregnancy occurs or about contraception and HIV-related matters with their children, nor had they discussed nocturnal emission with their sons. While not a single father had discussed menstruation with their daughter, some two-thirds of mothers had done so, but the content of this discussion focused overwhelmingly on the mechanics of using the "cloth" and instructions about not entering a temple or the kitchen during menstruation. 


\section{Chapter 3}

\section{Exposure to and perceptions about the intervention}

This chapter briefly describes the objectives of our intervention, the design of the intervention project, the main components of the intervention and the challenges faced in implementing the project. It also describes the extent to which parents were indeed exposed to the intervention, their experiences of participating in the intervention, and the extent to which their children attended the joint parent-child sessions.

\section{Objectives}

This pilot intervention aimed to engage parents in adopting less hierarchical socialisation practices towards their adolescent children and communicating more effectively with them. The specific objective was to design and pilot an intervention that would:

- Build parents' knowledge about adolescent health and development, the role parents play in influencing their children's transition into adult life and the importance of gender-egalitarian socialisation;

- Develop parenting practices that encourage the exercise of agency among sons and daughters; encourage better interaction between parents and children; and encourage the use of nonviolent forms of disciplining children; and

- Enable parents to communicate more openly with their adolescent sons and daughters, particularly on matters related to physical maturation and $\mathrm{SRH}$.

\section{Intervention design}

The intervention served mothers and fathers of unmarried adolescent girls and boys aged 13-17. It was delivered through a partnership with a local NGO, Geeta Mahila Uthan Samiti (GMUS), working in Bhojpur district. GMUS identified and supported locally recruited peer facilitators to implement sessions at village level and together with CEDPA India, trained these peer facilitators to conduct the intervention.

\section{Designing the curriculum}

At the time the project was initiated, there were no curriculums available in India that aimed to engage parents. Hence a first step was to develop an appropriate curriculum. CEDPA India, in partnership with the Population Council, reviewed available curriculums and opted to adapt syllabuses from two programmes: one implemented among parents in Senegal (Improving the communication between parents and adolescent in reproductive health and HIV/ AIDS) implemented by CEDPA and the Population Council (the intervention programme focused on parents and on HIV vulnerability) (Diop and Diagne, 2008); and a second implemented among adolescent girls in India (the Better Life Options programme) intended to empower adolescents, transform gender norms and encourage child-parent communication (CEDPA, 2000). CEDPA India synthesised the key lessons from each of these syllabuses, adapted them for implementation among parents, and created a curriculum comprising a total of 16 sessions for mothers, 16 sessions for fathers, and 4 sessions in which adolescent children of participants were also invited to attend. Sessions for parents included a total of 16 specific topics, notably, understanding adolescence, the importance of self-identity and self-worth among adolescents, gender issues and gender-egalitarian socialisation of children, friendship and peer pressure, stress management, conflict resolution, physical maturation and growing up concerns among adolescents, sexual health and identifying risk-taking behaviours, early marriage and its consequences, contraception, HIV and infection, gender-based violence and exploitation, substance abuse and effective communication with children ("Let's talk with our children"). 


\section{Building local capacity to implement the intervention}

CEDPA India put considerable emphasis on building the capacity of both the local leadership of the partner NGO, GMUS, and the peer facilitators who were engaged in delivering the intervention at village level. They also provided on-going supportive supervision throughout the course of the intervention. As a first step, it oriented and trained staff from GMUS about the project, its rationale and the role of GMUS in conducting the intervention. GMUS was tasked with identifying appropriate male and female facilitators from the study settings who had experience working on youth issues and who would deliver intervention sessions at field level.

During a second stage of capacity building, CEDPA India conducted the training of peer facilitators together with resource persons from GMUS. Peer facilitators were oriented about the intervention and its rationale, about adolescent health and development and the role of parents in ensuring a healthy transition to adulthood of their adolescent children. Sessions were largely interactive, with peer facilitators conducting mock sessions, responding to likely questions from parents and learning how to organize sessions, ensure attendance and ensure that sessions were interactive. The training also aimed to build peer educators' confidence about effective facilitation of sessions with the parents.

Refresher training was conducted from time to time during the intervention period. Thus, for example, immediately prior to conducting sessions on SRH and how to communicate sensitive matters with children, refresher training was provided that reviewed with peer facilitators the issues to be covered and the methodology through which the issues should be conveyed. The main objective of this training was to ensure that peer educators were sufficiently equipped to convey sensitive matters to parents, respond to questions and communicate ideas without embarrassment.

Finally, the intervention was extensively monitored. CEDPA India monitored the quality of training by peer educators and local NGO staff members, provided supportive feedback to them and assisted them in resolving problems.

\section{The intervention programme}

The intervention programme was designed for implementation over a five-month period, but in some villages, owing to the need for rescheduling of sessions, the programme lasted for nine months. It had two major components: the first consisted of a group-based initiative that sought to provide mothers and fathers (in separate groups) opportunities to gain exposure to issues relating to effective parenting and their roles in ensuring a successful transition to adulthood of their sons and daughters. Indeed, it gave parents an opportunity to reflect upon traditional norms inhibiting parent-child communication and to overcome such factors as limited awareness, discomfort and other obstacles preventing open parent-child communication about sensitive matters; the second component of the intervention included opportunities for parent-child communication, with four sessions reserved for joint sessions between each parent and a son or daughter aged 13-17.

\section{Group sessions}

Peer educators prepared lists of all households containing adolescent girls or boys aged 13-17, and they approached mothers and fathers of these adolescents for their participation in project activities. They held group sessions for mothers and fathers in each of the intervention villages. In each intervention village, groups of parents, on average comprising 20 parents, were enrolled to attend these sessions. In big villages, sessions were held on a weekly or fortnightly basis in a convenient location. A female and male peer educator held separate sessions for mothers and fathers, respectively. Session timings were drawn up in consultation with participants, particularly for fathers, for whom sessions were conducted in many villages as early as 7 a.m. or as late as 8 p.m. in order to accommodate work schedules.

\section{Parent-child sessions}

In addition, at selected sites, peer facilitators, and CEDPA India and the GMUS project team organized Intergenerational Dialogue Sessions in which the mother, father and their son or daughter participated. Discussions at these sessions focused on specific topics, such as gender roles and responsibilities, consequences of early marriage and conflict resolution. The purpose of these sessions was to bring parents and their adolescent children together to discuss and exchange views, on the one hand, and learn to communicate on issues of concern, on the other. 


\section{Exposure to the intervention}

As mentioned earlier, the intervention comprised a total of 16 sessions conducted among mothers and fathers, respectively, and 4 sessions in which parents were invited to bring their son or daughter. The participants in the endline survey were probed about their awareness of and participation in the intervention. Findings suggest (Table 3.1) that awareness about the programme was not universal. Indeed, just two-thirds of mothers (64 percent) and half of fathers (49 percent) were aware, as seen in the endline survey, that an intervention focused on parent-child relationships (or an intervention implemented by CEDPA India or CEDPA India's local partner, GMUS) had been implemented in their village. On the whole, 31 percent and 24 percent of mothers and fathers, respectively, had enrolled in the sessions, but 4 percent and 7 percent of mothers and fathers, respectively, had discontinued their participation after attending just one session and were not considered, thus, to have participated in the intervention. In all, therefore, a total of just 117 mothers (27 percent) and 52 fathers (17 percent), who had attended at least two sessions, are considered to have participated in the intervention. Background characteristics of mothers and fathers who had participated in intervention activities, that is, attended two or more sessions of the intervention, confirm that, by and large, parents who had participated in the intervention resembled those who had not done so (see Appendix 2). Among mothers, however, some differences were observed. Compared with non-participant mothers, participants were from economically poorer households (a mean standard of living index of 16 versus 18 among non-participants), were more likely to belong to scheduled caste families (34 percent versus 14 percent among non-participants), and were more likely to be engaged in unpaid or paid work (57 percent versus 42 percent among non-participants).

Interviews with parents and guardians suggest that in several cases, other family members (adolescents' grandmother or grandfather, brother or sister-in-law) were the ones who had attended one or more sessions. Indeed, 8 and 9 percent of mothers and fathers, respectively, reported participation of other family members. As the intervention was not intended for other household members, no data were collected from these individuals, and our analysis focuses specifically on the perspectives of parents and guardians.

Table 3.1: Parents' awareness of and exposure to the intervention and regularity of attendance of intervention activities, endline survey

\begin{tabular}{lcc}
\hline & Mothers (N=457) & Fathers (N=307) \\
\hline Aware that the intervention had been implemented & 64.1 & 48.9 \\
Respondent participated in the project (two or more sessions) & 27.2 & 16.8 \\
Respondent participated in just one session (and is not considered & 4.0 & 7.0 \\
to have participated) & 7.6 & 8.9 \\
Someone else in the family participated in the project & & \\
\hline
\end{tabular}

With regard to adolescents' exposure to the intervention, findings suggest that in many instances, adolescent children did not attend the joint sessions (Table 3.2). Indeed, while 27 percent of mothers had participated in the intervention, just 21 percent of (all) mothers reported that their son or daughter had attended even one of the joint sessions. While 17 percent of fathers had participated in the intervention, even fewer fathers reported attendance of son or daughter (13 percent). Notably, while nearly the same percentages of mothers reported that a son or a daughter had attended the joint sessions (11 percent each), fathers were somewhat more likely to report that a son had attended, (10 percent) than a daughter ( 6 percent). The reports of adolescents were mostly corroborated by the reports of parents; just 23 percent of daughters and 21 percent of sons who were interviewed for the endline survey reported that they or their sibling had attended at least one joint session, and just 16 percent of daughters and 15 percent of sons reported that they had attended a session.

\section{Parents' perceptions about the intervention}

Parents' perceptions were explored in the course of the endline survey through questions that assessed their reasons for joining the intervention, the size of average sessions attended, their perceptions about the length of the intervention and their assessment of the skill of the facilitator in conducting the curriculum (Table 3.3). Given the small number of fathers who participated in the intervention, we advise caution in interpreting findings from fathers with regard to their perceptions about the intervention. 
Table 3.2: Adolescents' exposure to the intervention as reported by parents and adolescents, endline survey

\begin{tabular}{|c|c|c|}
\hline Parents' report & Mothers $(\mathrm{N}=457)$ & Fathers $(\mathrm{N}=307)$ \\
\hline $\begin{array}{l}\text { Son and/or daughter attended at least one joint } \\
\text { parent/other family member }\end{array}$ & 20.5 & 13.0 \\
\hline Son attended & 9.6 & 7.0 \\
\hline Daughter attended & 9.5 & 3.3 \\
\hline Both attended & 1.4 & 2.7 \\
\hline Adolescents' report & Daughters (N=322) & Sons $(N=374)$ \\
\hline $\begin{array}{l}\text { Respondent and/or a sibling attended at least o } \\
\text { parent/other family member }\end{array}$ & 23.1 & 20.7 \\
\hline Respondent attended at least one joint session & 15.6 & 15.3 \\
\hline
\end{tabular}

Table 3.3: Perceptions about the programme and reasons for participating

Mothers (N=117)

\section{Reasons for joining the group}

To learn about ways of improving communications with adolescent children

To learn new things

To learn how to cope with children's problems

\section{Perceptions about the total duration of the programme ${ }^{1}$}

$$
\begin{aligned}
& \text { 1-3 months } \\
& \text { 4-6 months }
\end{aligned}
$$

7-10 months

The group leader/facilitator explained things clearly

$\begin{array}{rr}43.5 & 49.0 \\ 85.5 & 100.0 \\ 33.1 & 19.2 \\ & \\ 11.3 & 17.3 \\ 73.4 & 59.6 \\ 5.6 & 9.6 \\ 96.8 & 90.2\end{array}$

Note: ${ }^{1}$ Among mothers, 1.6 percent could not say how many parents usually attended the sessions; 9.7 percent of mothers and 13.5 percent of fathers were unaware of the total duration of the programme.

Parents had, for the most part, general expectations from the project. Almost all (86 percent of mothers and all fathers) had participated in the programme in order to "learn new things". About half of all participating parents, however, had joined the programme to learn how to communicate better with their adolescent children (44 percent of mothers and 49 percent of fathers) and how to cope with their children's problems (33 percent of mothers and 19 percent of fathers).

Most parents reported that the sessions had continued for 4-6 months (73 percent of mothers and 60 percent of fathers) although a minority reported that sessions had lasted just 1-3 months (11 percent of mothers and 17 percent of fathers). A few parents (6 percent of mothers and 10 percent of fathers) reported, in addition, that sessions had continued beyond six months, owing to, in some instances, temporary suspension of sessions, because they coincided with peak agricultural activities, and hence, they were implemented for a longer period than the scheduled five months.

Almost all parents rated the sessions very positively: almost all parents were satisfied with the skill of the facilitator (90-97 percent). 


\section{Extent of exposure to the curriculum for parents among participating parents, and perceptions of parents and adolescents about the usefulness of the curriculum}

We also explored participating parents' reported attendance during the sessions in which the 16 topics were discussed and their assessment of the topics to which they were exposed. Specifically, we probed whether what was taught in the sessions that they had attended was useful; whether they had learned anything new in the sessions they had attended; whether it was the first time that a particular topic had been discussed with them; and whether they were embarrassed by or uncomfortable with the topic discussed in any session that they had attended. Results are presented in Table 3.4. Adolescents, similarly, were probed about their perceptions about the joint sessions that they had attended. Specifically, they were probed about whether they found the sessions useful, whether they learnt anything new in the sessions that they attended and whether they were comfortable attending those sessions.

Table 3.4: Extent of exposure to the curriculum and perceptions of parents and adolescents about the usefulness of the curriculum

\begin{tabular}{|c|c|c|}
\hline Participating Parents & Mothers (N=117) & Fathers $(\mathrm{N}=\mathbf{5 2})$ \\
\hline \multicolumn{3}{|l|}{ Number of topics to which participants were exposed } \\
\hline $2-4$ & 19.6 & 28.4 \\
\hline $5-7$ & 15.5 & 35.6 \\
\hline $8-10$ & 17.2 & 18.7 \\
\hline $11-12$ & 20.5 & 9.2 \\
\hline 13 or more & 27.2 & 8.1 \\
\hline \multicolumn{3}{|l|}{ Of the sessions attended } \\
\hline Percent who found all the topics (to which they were exposed) useful & 91.0 & 94.9 \\
\hline Percent who learned new things in all the sessions that they attended & 84.4 & 86.8 \\
\hline $\begin{array}{l}\text { Percent for whom this was the first time that someone had discussed the } \\
\text { topics included in the curriculum with them }\end{array}$ & 71.3 & 47.6 \\
\hline $\begin{array}{l}\text { Percent who did not feel uncomfortable/shy when various topics were } \\
\text { discussed in any session attended }\end{array}$ & 66.4 & 66.1 \\
\hline Participating Adolescents & Daughters ( $N=48)$ & Sons $(\mathrm{N}=49)$ \\
\hline Percent who found all the sessions that they attended useful & 98.8 & 98.3 \\
\hline Percent who learned new things in all the sessions that they attended & 88.7 & 96.6 \\
\hline Percent who did not feel discomfort during sessions attended & 72.1 & 75.4 \\
\hline
\end{tabular}

Findings suggest that exposure of participating parents to the topics in the curriculum was, by and large, moderate. As Table 3.4 shows, about two-thirds ( 65 percent) of mothers and far fewer fathers ( 36 percent) were exposed to 8 or more of the 16 topics included in the curriculum, and only one-quarter of mothers ( 27 percent) and fewer than one-tenth (8 percent) of fathers were exposed to 13 or more topics included in the curriculum. The gender divide was evident, with fathers far less likely than mothers to have been exposed to the various topics included in the curriculum.

Although participating fathers had attended fewer sessions than had participating mothers, their assessments of the quality of the intervention was, for the most part, similar. As much as 91 percent and 95 percent of mothers and fathers, respectively, reported that all the topics to which they had been exposed were useful and 84 percent and 87 percent of mothers and fathers, respectively, reported that they had learned new things in all the sessions they had attended. Somewhat fewer-71 percent of mothers and 48 percent of fathers-reported that they had been exposed to information for the first time in all the sessions they had attended. Clearly, fathers, who were better educated and less confined to the home, had multiple sources of information about adolescent health and development and $\mathrm{SRH}$ matters. Finally, although efforts were made to reduce discomfort when such topics as communicating about 
physical maturation, pregnancy and contraception were discussed with children, only 66 percent each of mothers and fathers reported that they did not feel shy or uncomfortable in any of the sessions they had attended.

As seen in Table 3.4, only few of the interviewed adolescents had attended the intervention. However, those who had done so assessed the programme favourably in terms of its usefulness (99 percent of daughters and 98 percent of sons), imparting of new information (89 percent of daughters and 97 percent of sons) and delivery in ways that minimised discomfort (72 percent of daughters and75 percent of sons).

\section{Challenges faced in implementing intervention activities}

We faced a number of challenges in implementing the intervention. Above all, the limited interest in an intervention on parenting in this gendered and hierarchical socio-cultural context made it difficult for programme implementers to convince parents about how exposure to an intervention that focused on building better parenting and communication skills and relations with adolescent children may benefit their children's health and development. As a result, large proportions of eligible parents did not agree to join the intervention, many who were enrolled did not attend regularly and those who did attend often suggested that the topic was irrelevant for them or that they would attend if the intervention was linked with livelihood opportunities. Fathers, in particular, were sceptical about the usefulness of the intervention, and it was often difficult to convey new ideas to mothers and fathers, especially those that involved communicating with children about SRH matters and those that called for greater exercise of agency among girls.

Second, despite the team's best efforts, it was difficult to reach all community members with adolescent children to inform them about the intervention. In this poor rural setting, many parents worked long hours in agriculture or in jobs that required commuting to nearby urban areas. Reaching them in the daytime and even in the evenings was often difficult. Even when available, housework commitments among mothers and alcohol consumption among fathers (and a few mothers) made it difficult to access many parents. Some fathers, moreover, had temporarily migrated away from the village and were not in residence for much of the time during which the intervention was implemented. As such, project teams were unable to reach all parents to inform them about the study and were unable to arrive at an acceptable time when sessions could be held. As a result of lack of time, not all parents, particularly fathers, who had enrolled in the intervention attended most of its sessions.

Third, as mentioned earlier, in several cases, other adult family members attended the sessions instead of the enrolled parent. As a result, focused attention on parents was not achieved in most groups.

Fourth, it was difficult to identify local women and men who displayed both leadership qualities and willingness to undertake the role of peer facilitators. CEDPA India and GMUS made a concerted effort to identify appropriate facilitators, build their skills and support them at all stages of the intervention. However, there was considerable turnover among these peer mentors, and several peer mentors who agreed to take on the responsibility found it difficult to communicate intervention messages in a simple and convincing way, which resulted in GMUS taking on much of the responsibility for programme implementation.

Finally, we note that since this was a 16-session pilot, we recognize that in a setting as conservative as rural Bihar, it is likely that the duration of the intervention was insufficient to bring about changes in parental and community norms and practices.

\section{Summary}

Although two-thirds of mothers and half of fathers of adolescents aged 13-17 were aware of the intervention, just one-quarter of mothers and one-sixth of fathers had participated in the intervention. While participating parents were, by and large, similar to those who had not participated in the intervention, we note that participating mothers were more likely to have come from poorer households and more likely to have been engaged in wage-earning activities than non-participating mothers.

Among those who had participated in the intervention, moreover, exposure to the curriculum was far from universal. Just two-thirds (65 percent) of mothers and far fewer fathers ( 36 percent) were exposed to 8 or more of the 16 topics included in the curriculum, and only one-quarter of mothers (27 percent) and fewer than one-tenth ( 8 percent) of fathers were exposed to all 13 or more topics included in the curriculum. The gender divide was evident, with fathers far less likely than mothers to have been exposed to the curriculum. 
Adolescent participation in the parent-child joint sessions was limited. Indeed, just 21 percent of mothers and 13 percent of fathers reported that their son or daughter had attended one or more of the four joint sessions. Reports of adolescents were mostly corroborated by the reports of parents-just 23 percent of daughters and 21 percent of sons who were interviewed for the endline survey reported that they or their sibling had attended at least one joint session.

Although participating fathers had attended fewer sessions than had participating mothers, their assessments of the quality of the intervention was similar on most issues. Most parents agreed, for example, that the facilitator was skilled. The large majority-well over four in five-of mothers and fathers found all the topics to which they had been exposed useful, and had learned new things in all the sessions they had attended. More than two-thirds of all mothers, and half of all fathers reported that they had been exposed to the information conveyed in the intervention for the first time in all the sessions they had attended. Finally, although efforts were made to reduce discomfort when such topics as communicating about physical maturation, pregnancy and contraception were discussed with children, about one-third of both mothers and fathers reported that they had felt shy or uncomfortable in some of the sessions they had attended.

In a similar vein, while attendance of sons and daughters was limited, their assessment of the quality of the intervention was positive. Most of them reported that they had learned something new, that the sessions were useful and that the sessions were delivered so that they did not feel uncomfortable when sensitive issues were being discussed.

We faced a number of challenges in implementing the intervention. It was difficult for programme implementers to convince parents about how exposure to an intervention that focused on building better parenting and communication skills and relations with adolescent children may benefit their children's health and development. In this poor rural setting, moreover, many parents worked long hours in agriculture or in jobs that required temporary out-migration or commuting to nearby urban areas, and reaching them in the daytime and even in evenings was often difficult. As a result, not all parents could be reached, and many who had enrolled in the intervention had not attended most of its sessions; in their place, other adult family members attended the sessions, and, thus, focused attention on parents was not achieved in most groups. We encountered difficulties in identifying local women and men who displayed leadership qualities, were willing to undertake the role of peer facilitators, remained with the project throughout and were skilled in communicating intervention messages. Finally, given the gendered and hierarchical context, it was difficult to effect changes in parental and community norms and practices in a 16-session pilot. 


\section{Chapter 4}

\section{Effects of the intervention: Parental knowledge, attitudes, socialisation practices and parent-child communication}

The goal of our intervention was to equip parents with new ideas about parenting by enhancing their knowledge and changing their attitudes and practices related to parent-child relationships. This chapter presents findings with regard to the effects of exposure to the intervention on parents' awareness of issues relating to physical maturation and SRH as well as on their gender-role attitudes and perceptions about socialisation practices and communication with adolescents. It also sheds light on the effect that the intervention had on their practices, notably with regard to socialisation of adolescents and communication with them on issues of physical maturation and SRH. In this chapter, we present perspectives of both parents and adolescents with regard to changes in behaviour.

\section{Methodology}

We measure effects on parents by comparing baseline and endline survey measures for the parents in study villages who had participated in the intervention with those who had not. Data are available from both the baseline survey and the endline survey for a total of 457 mothers and 307 fathers. These include 117 mothers who had participated in intervention sessions and 340 who had not been exposed to the intervention, and, correspondingly, 52 fathers who had participated in the intervention and 255 who had not been exposed to the intervention. Given that the number of fathers who participated in our intervention was too small to enable a rigorous assessment of the effect that participation in the intervention had on them, this chapter provides findings from mothers and fathers, with the provison that findings from fathers are illustrative and must be interpreted cautiously.

To ascertain the degree of change in outcome indicators reflecting parents' awareness, attitudes and practices attributable to exposure to the intervention, that is, to assess the net effect of exposure to the intervention on these indicators, we use difference-in-differences (DiD) estimators (Ashenfelter, 1978; Ashenfelter and Card, 1985). The DiD method contrasts the difference in average outcome in the exposed and unexposed groups from the baseline and endline surveys. In this way, the model isolates the effect of exposure to the intervention by cancelling out effects of other factors external to the intervention that both groups may have experienced in the period between the baseline and endline surveys. A key assumption of the DiD model is that other factors external to the intervention that have the potential to affect outcome measures (for example, introduction of new programmes) would affect both those exposed and those not exposed to the intervention in a similar way. The model also isolates the effect of any pre-existing differences between the two groups; t-tests have been performed that assess the extent to which the relative improvements in outcome in the exposed and unexposed groups are statistically significant.

Mathematically, a DiD model can be represented as follows:

$\operatorname{EFFECT}=\left(Y_{e, 1}-Y_{e, 0}\right)-\left(Y_{u, 1}-Y_{u, 0}\right)$

Where $Y_{e, 0}$ and $Y_{e, 1}$ are the outcome measures in the baseline and endline survey for those who participated in the intervention, and $Y_{u, 1}$ and $Y_{u, 0}$ are the outcome measures in the baseline and endline survey for those who did not participate in the intervention. 


\section{A. Effects of the intervention: parental knowledge}

\section{Effects of the intervention on parents' awareness about physical maturation and SRH matters}

The parents' curriculum focused to a considerable extent on raising parental awareness of adolescent health and development, and, notably, physical maturation and SRH matters. Table 4.1 presents mothers' awareness and fathers' awareness about physical maturation and SRH matters at the time of the baseline and endline interviews.

Findings suggest that, among mothers, there has been a significant overall improvement in the awareness of physical maturation issues over time, as reflected by the increase in the mean score from the baseline survey to that in the endline survey. The increase, however, has taken place among both the participant group and the

Table 4.1: Awareness about physical maturation and other SRH matters among participant and non-participant parents at baseline and endline

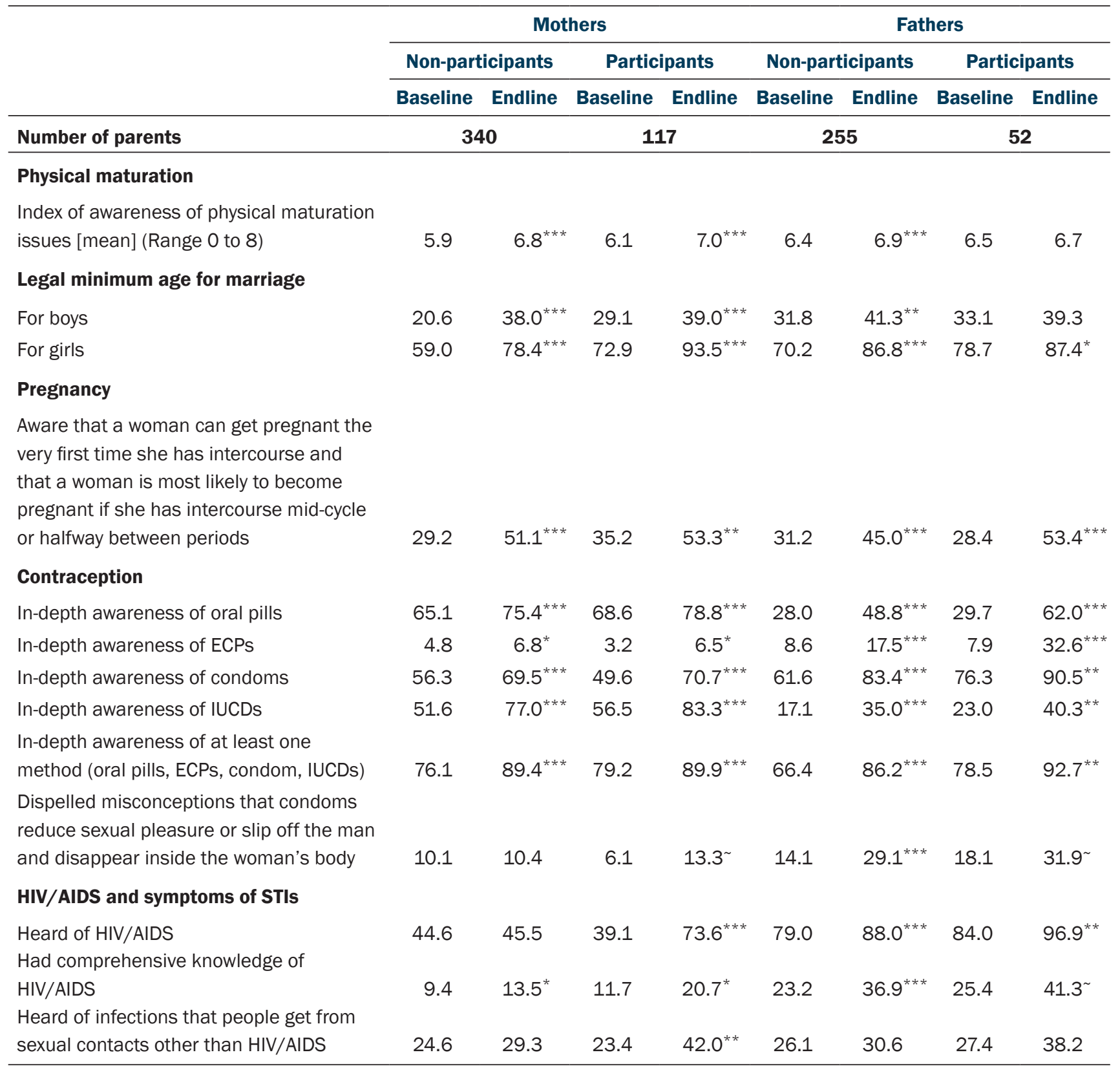

Note: $\sim p<=0.10,{ }^{*} p<=0.05,{ }^{* *} p<=0.01,{ }^{* *} p<=0.001$. Differences in the means between endline and baseline are based on paired t-tests. 
non-participant group of mothers in nearly the same proportion (seen in an increase in the score from 6 to 7 for each group of mothers). Among fathers, awareness levels increased more modestly in both groups between the baseline and endline survey (from 6.4 to 6.9 for non-participant fathers and from 6.5 to 6.7 for participant fathers). The surveys also gauged parents' awareness of the legal minimum age for marriage for boys and girls. Awareness increased significantly among both participants and non-participants. While 73 percent of participant mothers and 59 percent of non-participant mothers were aware of the legal minimum age for marriage for girls in the baseline survey, percentages showed significant increases to 94 and 78, respectively, in the endline survey. Percentages showing awareness of the legal minimum age for marriage for boys also increased significantly from the baseline to the endline survey-from 29 to 39 percent among participant mothers, and from 21 to 38 percent among nonparticipant mothers. As seen in Table 4.1, approximately as many fathers as mothers were aware of the legal minimum age for marriage for girls and boys, and increases over the course of the intervention were not significant among participants.

With regard to awareness about pregnancy-related matters by parents, findings once again suggest that there has been a significant increase in percentages of parents showing awareness of pregnancy-related issues from the baseline to the endline survey. Again, similar increases were observed among exposed and unexposed mothers (from 35 percent to 53 percent, and from 29 percent to 51 percent, respectively). Among fathers, similarly, awareness of pregnancy-related issues increased significantly among both groups, from 28 percent to 53 percent among those exposed to the intervention and from 31 percent to 45 percent among those who did not participate in the intervention.

In-depth awareness of selected contraceptive methods increased significantly over the period between the baseline and the endline survey among both intervention participants and intervention non-participants and among both mothers and fathers. Thus, in-depth awareness of at least one method increased significantly and similarly for both participant and non-participant groups (from 79 percent to 90 percent among participating mothers; from 76 percent to 89 percent among non-participating mothers; from 79 percent to 93 percent among participant fathers; and from 66 percent to 86 percent among non-participant fathers). Findings show, moreover, that percentages of mothers who had dispelled misconceptions about condoms increased mildly but significantly among participant mothers (from 6 percent to 13 percent), but remained unchanged among non-participant mothers (10 percent in both surveys). In contrast, larger increases were recorded among fathers (from 18 percent to 32 percent among participant fathers and from 14 percent to 29 percent among non-participant fathers).

Finally, with regard to awareness of HIV/AIDS and other STIs, findings show that there were differences in the pattern of changes between participant and non-participant parents in some aspects from the baseline to the endline survey. Awareness of HIV/AIDS increased significantly, from 39 percent to 74 percent among participant mothers, but remained unchanged among non-participant mothers (45 percent to 46 percent). Comprehensive awareness of HIV/AIDS increased among both groups of mothers, though increases were steeper among participant mothers (12 percent to 21 percent) than non-participant mothers (9 percent to 14 percent). Awareness of STIS other than HIV also increased consistently among participant mothers, from 23 percent to 42 percent, compared with a much milder increase among non-participant mothers (from 25 percent to 29 percent).

Most fathers had heard of HIV in the baseline survey (79 percent of non-participant fathers and 84 percent of participant fathers); even so, percentages of fathers who reported awareness of HIV had increased significantly in both groups by the time the endline survey was conducted (an increase to 97 percent among intervention participants and 88 percent among non-participants). Comprehensive knowledge of HIV/AIDS had also increased significantly in both groups (from 25 percent to 41percent among participants and from 23 percent to 37 percent among non-participants). Awareness of STIs increased from 27 percent to 38 percent among participant fathers and, more mildly, from 26 percent to 31 percent among non-participant fathers.

Only for a few indicators could change in awareness levels be attributed to the intervention. The results of the DiD model, presented in Figure 4.1, show the extent of change in these indicators of awareness among participant and non-participant mothers and fathers (non-significant effects are not shown). ${ }^{1}$ With regard to mothers, they confirm that although a significant change was observed in most measures of awareness, in only two instances was the

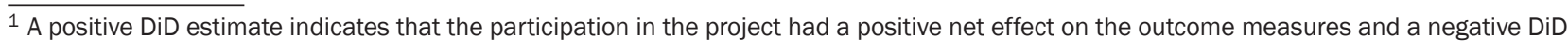
estimate suggests a negative net effect on the outcome measures.
} 
DiD estimate significant, and the change significantly greater among participant than non-participant mothers and attributable to participation in the intervention. Indeed, change attributable to the intervention was significant only for in-depth awareness of condoms and awareness of HIV/AIDS. Specifically, findings may be interpreted to imply that among all participant mothers, 8 of the 21 percentage point increase in in-depth awareness of condoms ( 38 percent of the increase in awareness) and 34 of the 35 percentage point increase in HIV awareness (or 97 percent of the increase in awareness) was attributable to the intervention. Among participant fathers too, change attributable to the intervention was significant only in two instances-awareness of pregnancy-related matters and in-depth awareness of emergency contraceptive pills: 11 of the 25 percentage point increase in awareness of pregnancyrelated matters (44 percent of the increase in awareness) and 16 of the 25 percentage point increase in in-depth awareness of emergency contraception (64 percent of the increase in awareness) could be said to be attributed to the intervention.

Figure 4.1: Effects of exposure to the intervention programme on parents' awareness about physical maturation and other SRH matters

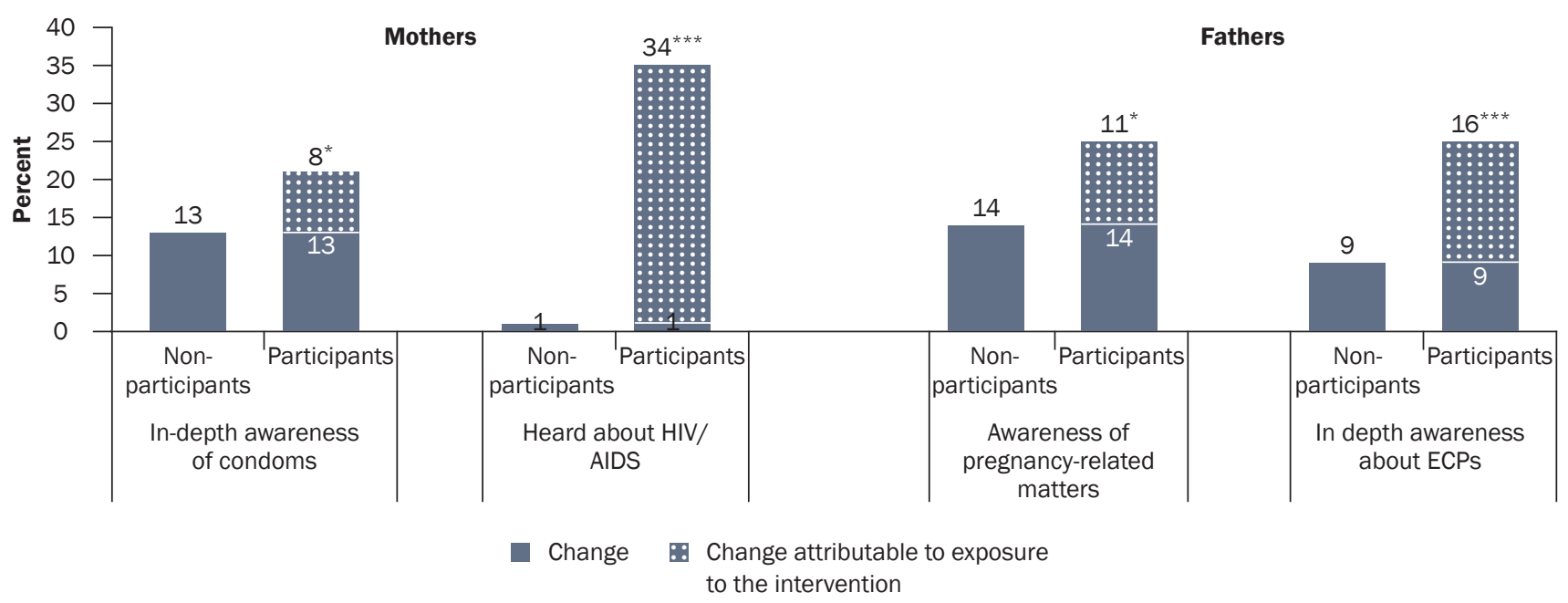

Note: $t$-test for DiD estimate $>0$ significant at ${ }^{*} p<=0.05,{ }^{* *} p<=0.001$. Each bar represents change between baseline and endline. DiD estimate: Change among intervention participants minus change among non-participants.

\section{B. Effects of exposure to the intervention on parents' gender-role attitudes, perceptions about socialisation practices and about communication with adolescents}

The intervention focused on changing parental attitudes on a number of issues, for example, attitudes about the roles of women and men, in general, their perceptions about socialisation practices, including gender-equitable roles in childrearing, their perceptions about parent-child communication and the norms they hold about communication with children about SRH matters.

\section{Gender-role attitudes}

Findings presented in Table 4.2 reflect the percentages of mothers and fathers reporting gender-egalitarian attitudes. Changes in gender-role attitudes were mixed. Attitudes such as childrearing is the mother's responsibility, a married woman has to take her husband's permission to visit her natal family and needs to obtain his permission for "most things" remained inegalitarian among both participant and non-participant mothers and fathers as seen from the responses in the endline survey. Among mothers, for example, even in the endline survey, just 3 percent of non-participant mothers and 6 percent of participant mothers agreed that a woman need not seek her husband's permission to visit her natal family, 8 percent of non-participant mothers and 11 percent of participant mothers held that caring for children was not just a mother's responsibility, and 22 percent of non-participant mothers versus 18 percent of participant mothers held that a woman does not need her husband's permission for "most 
Table 4.2: Gender role expressed by participant and non-participant parents at baseline and endline

\begin{tabular}{|c|c|c|c|c|c|c|c|c|}
\hline & \multicolumn{4}{|c|}{ Mothers } & \multicolumn{4}{|c|}{ Fathers } \\
\hline & \multicolumn{2}{|c|}{ Non-participants } & \multicolumn{2}{|c|}{ Participants } & \multicolumn{2}{|c|}{ Non-participants } & \multicolumn{2}{|c|}{ Participants } \\
\hline & Baseline & Endline & Baseline & Endline & Baseline & Endline & Baseline & Endline \\
\hline Number of parents & \multicolumn{2}{|c|}{340} & \multicolumn{2}{|c|}{117} & \multicolumn{2}{|c|}{255} & \multicolumn{2}{|c|}{52} \\
\hline \multicolumn{9}{|c|}{ Attitudes about gender roles (Percent reporting egalitarian attitudes on each item) } \\
\hline $\begin{array}{l}\text { It is okay for a man to hit his wife if she } \\
\text { won't have sex with him (disagree) }\end{array}$ & 95.4 & 97.1 & 95.1 & 98.2 & 92.1 & 93.9 & 90.6 & 89.9 \\
\hline $\begin{array}{l}\text { A man should have the final word about } \\
\text { decisions related to household matters } \\
\text { (disagree) }\end{array}$ & 63.2 & $83.2^{* * *}$ & 64.2 & $82.4^{* *}$ & 55.0 & $68.7^{* * *}$ & 53.9 & $72.7^{*}$ \\
\hline $\begin{array}{l}\text { Giving the children a bath and feeding } \\
\text { them are the mother's responsibility } \\
\text { (disagree) }\end{array}$ & 11.1 & 8.3 & 8.8 & 11.3 & 37.6 & 42.8 & 37.0 & $51.0^{*}$ \\
\hline $\begin{array}{l}\text { A married woman should not need to as } \\
\text { her husband for permission to visit her } \\
\text { parents/family (agree) }\end{array}$ & 6.8 & $3.2^{*}$ & 7.2 & 5.5 & 9.9 & $5.4^{\sim}$ & 6.6 & 3.4 \\
\hline $\begin{array}{l}\text { A woman should obtain her husband's } \\
\text { permission for most things (disagree) }\end{array}$ & 5.9 & $22.1^{* * *}$ & 6.9 & $18.1^{* *}$ & 14.4 & 15.9 & 12.1 & 11.7 \\
\hline Any three of the above five situations & 15.3 & $27.5^{* * *}$ & 15.2 & $25.3^{*}$ & 36.2 & $42.8^{\sim}$ & 37.2 & 44.3 \\
\hline
\end{tabular}

Note: $\sim p<=0.10,{ }^{*} p<=0.05,{ }^{* *} p<=0.01,{ }^{* *} p<=0.001$. Differences in the means between endline and baseline are based on paired t-tests.

things". Among fathers, at the time of the endline survey, 5 percent and 3 percent of non-participant and participant fathers, respectively, perceived that a woman need not seek her husband's permission to visit her natal family; 16 percent and 12 percent of non-participant and participant fathers, respectively, felt she should obtain her husband's permission for most things; and about half of all fathers ( 43 percent and 51 percent of non-participants and participants, respectively) believed that childcare is not the mother's responsibility only.

At the other extreme, in the endline survey, almost all mothers and fathers perceived that it was unacceptable for a man to beat his wife if she does not have sex with him (97 percent and 98 percent of non-participant and participant mothers, respectively, and 94 percent and 90 percent of non-participant and participant fathers, respectively).

On the whole, for mothers, attitudes had become more egalitarian on just two indicators: significantly more mothers at the time of the endline survey than at the baseline survey agreed that it was not necessary for a man to have the final word about decisions related to household matters (up from 63 percent to 83 percent for non-participant mothers and 64 percent to 82 percent for participant mothers), and that a woman did not need to seek her husband's permission for "most things" (up from 6 percent to 22 percent for non-participant mothers and 7 percent to18 percent for participant mothers from the baseline to the endline survey). Significantly, more fathers, too, in both groups, agreed that it was not necessary for a man to have the final word about decisions related to household matters (up from 55 percent to 69 percent for non-participant fathers and 54 percent to 73 percent for participant fathers from the baseline to the endline survey) In addition, significantly more fathers who had been exposed to the intervention agreed that fathers, too, should participate in childrearing (from 37 percent to 51 percent from the baseline to the endline survey). Our summary measure however suggests that percentages of mothers who held egalitarian attitudes on three or more indicators increased from 15 to 25 among participant mothers, from 15 to 28 among non-participant mothers, from 37 to 44 among participant fathers and 36 to 43 among non-participant fathers.

In short, while attitudes had become more egalitarian among both participant and non-participant mothers and fathers on a few indicators, findings of the DiD model (not shown in figure form) suggest that where increases had taken place in percentages of mothers and fathers expressing egalitarian attitudes, these increases could not be attributed to the intervention. 


\section{Attitudes about involving children in decisions affecting their own life}

As seen in Chapter 3, the intervention sought to change attitudes of parents about the right of their children to have a say in their own lives. Table 4.3 presents measures capturing parents' attitudes about involving children in decisions affecting children's own lives. The measures explore whether decisions regarding children reflect parental control or children's own agency in such matters as whom and when children will marry. Findings confirm that in both surveys and among both groups, more parents favoured the involvement of boys in marriage-related decisions than they did the involvement of girls. Among mothers, there was a significant increase in percentages of both participant and non-participant groups who favoured girls' involvement in the two marital decisions and of participant mothers who favoured the involvement of boys in decisions on whom to marry. While 68 percent of non-participant mothers and 70 percent of participant mothers maintained in the baseline survey that girls should be involved in deciding whom they marry, by the time of the endline survey, 75 percent of non-participant mothers, compared with 88 percent of participant mothers, expressed this attitude. Among fathers, in contrast, the baseline survey showed that participating fathers were consistently more likely than non-participating fathers to have held egalitarian attitudes. While the endline survey reported more fathers as having gender-egalitarian attitudes than the baseline survey did, increases were significant in three of four statements among non-participants, and just one among participants.

The results of the DiD model presented in Figure 4.2 show that the effect of the intervention was significant in only two instances, both reflecting changes in attitudes of mothers; they confirm that the shift in attitudes about the acceptability of sons and daughters, respectively, having a say in the choice of their marriage partner was attributable to the intervention (non-significant effects are not shown). Specifically, of the 18 percentage point increase in the percentage of mothers who acknowledged the acceptability of sons and daughters, respectively, in playing a role in the selection of their marriage partner, 15 and 10 points were attributable to exposure to the intervention, suggesting that 83 percent and 56 percent of the change in these attitudes could be attributed to the intervention. Changes in other indicators observed for mothers and in all indicators for fathers were not attributable to the intervention.

Figure 4.2: Effects of exposure to the intervention programme on mothers' attitudes about involving children in decisions affecting their own lives

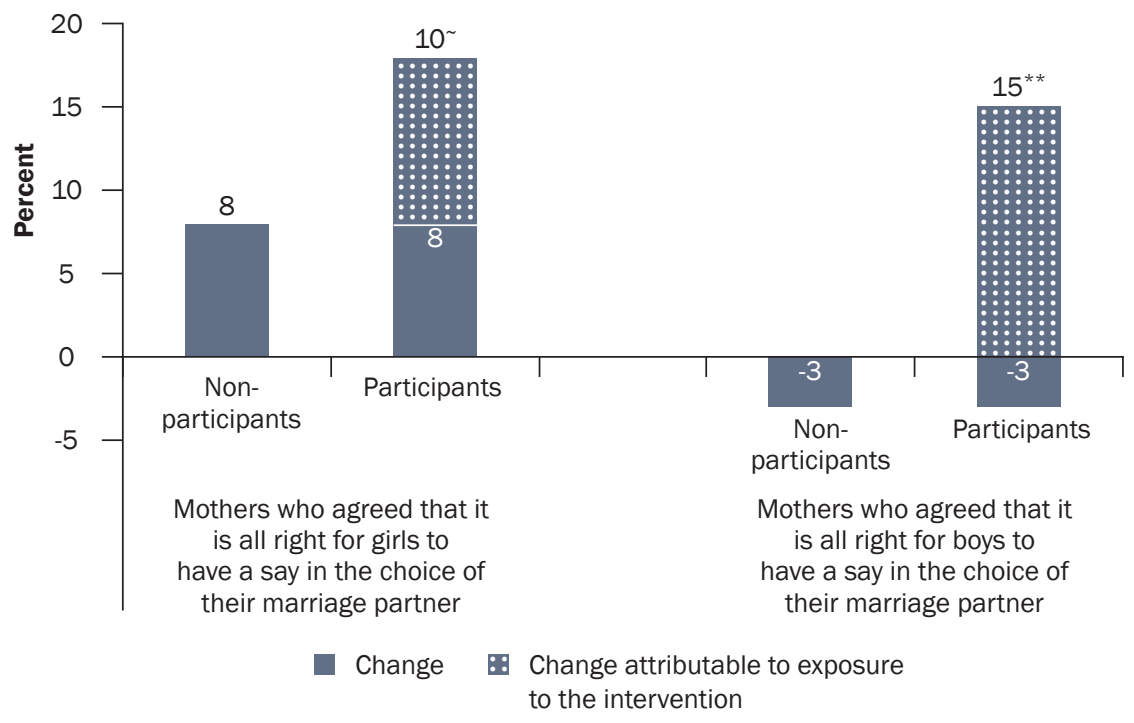

Note: $t$-test for DiD estimate $>0$ significant at $\sim p<=0.10,{ }^{* \star} p<=0.01$. Each bar represents change between baseline and endline. DiD estimate: Change among intervention participants minus change among non-participants.

\section{Attitudes about parents' responsibilities of informing children about non-sensitive matters (money, savings) and sensitive matters (physical maturation and SRH)}

One of the key aims of the intervention was to change parental perceptions about withholding information from children about sensitive SRH matters and, more specifically, to enable parents to recognise that informing children, 
Table 4.3: Attitudes about involving children in decisions affecting their own life expressed by participant and non-participant parents at baseline and endline

\begin{tabular}{|c|c|c|c|c|c|c|c|c|}
\hline & \multicolumn{4}{|c|}{ Mothers } & \multicolumn{4}{|c|}{ Fathers } \\
\hline & \multicolumn{2}{|c|}{ Non-participants } & \multicolumn{2}{|c|}{ Participants } & \multicolumn{2}{|c|}{ Non-participants } & \multicolumn{2}{|c|}{ Participants } \\
\hline & Baseline & Endline & Baseline & Endline & Baseline & Endline & Baseline & Endline \\
\hline Number of parents & \multicolumn{2}{|c|}{340} & \multicolumn{2}{|c|}{117} & \multicolumn{2}{|c|}{255} & \multicolumn{2}{|c|}{52} \\
\hline \multicolumn{9}{|c|}{$\begin{array}{l}\text { Attitudes about involving children in decisions affecting their own life } \\
\text { (Percent reporting egalitarian attitudes on each item) }\end{array}$} \\
\hline $\begin{array}{l}\text { It is all right for boys to have a say in the } \\
\text { choice of their marriage partner (agree) }\end{array}$ & 86.2 & 83.3 & 82.3 & $94.3^{* *}$ & 83.9 & 87.5 & 92.1 & 86.0 \\
\hline $\begin{array}{l}\text { It is all right for boys to have a say in wher } \\
\text { they want to marry (agree) }\end{array}$ & 85.6 & 81.5 & 83.3 & 89.3 & 76.4 & $86.9^{* * *}$ & 92.1 & $98.7^{\sim}$ \\
\hline $\begin{array}{l}\text { It is all right for girls to have a say in the } \\
\text { choice of their marriage partner (agree) }\end{array}$ & 67.6 & $75.2^{*}$ & 69.8 & $87.5^{* * *}$ & 71.0 & $81.6^{* *}$ & 78.2 & 88.2 \\
\hline $\begin{array}{l}\text { It is all right for girls to have a say in when } \\
\text { they want to marry (agree) }\end{array}$ & 67.9 & $74.8^{*}$ & 69.8 & $80.8^{*}$ & 59.6 & $71.1^{* *}$ & 69.8 & 74.6 \\
\hline
\end{tabular}

Note: $\sim p<=0.10,{ }^{*} p<=0.05,{ }^{* *} p<=0.01,{ }^{* *} p<=0.001$. Differences in the means between endline and baseline are based on paired t-tests.

at appropriate ages, about these matters is a key parental responsibility. Findings, presented in Table 4.4 suggest that there was a significant increase in the percentages of mothers and fathers-among both participants and non-participants-who believed that their children should be informed about sensitive matters such as physical maturation, menstruation, pregnancy and contraception. Among mothers, increases were consistently greater among participants than non-participants. The baseline survey shows, for example, that while just 13 percent of mothers who had not participated in the intervention and 14 percent of mothers who had participated in the intervention believed that daughters should be informed about physical maturation before puberty takes place, by the time of the endline survey, percentages had increased to 29 among non-participant mothers compared with 34 among participant mothers. With regard to menstruation, similarly, percentages of mothers who believed that daughters should be given information about menstruation before they experience it showed increases from 17 to 47 among participant mothers and from 18 to 32 among non-participant mothers between the baseline and the endline survey, respectively. Similarly, percentages of mothers who believed that daughters should be informed about pregnancy and contraception during adolescence increased from 9 to 36 and from 7 to 29 , respectively, among participant mothers, and far less spectacularly among non-participant mothers (13 to 24 for information on pregnancy and 7 to 21 for information on contraception). The summary index also shows that attitudes have become significantly more favourable, particularly among participant mothers (from a score of 1.0 to 2.3 of a total of 5) than non-participants (from 1.0 to 1.8).

With regard to sons, too, significantly more mothers reported in the endline survey than the baseline survey that they favoured the provision of information on sexual and reproductive matters to their sons. While increases from the baseline to the endline survey were somewhat more evident among participant than non-participant mothers, it was only in the case of the provision of information about pregnancy-related matters and contraception that the increases were considerably more evident among participant than non-participant mothers (from 15 percent to 37 percent, and from 9 percent to 36 percent, respectively, for participant mothers, and from 11 percent to 29 percent, and from 10 percent to 26 percent, respectively, for non-participant mothers). The summary index confirms moreover, that attitudes have become significantly more favourable among both participant mothers with regard to informing sons (from a score of 1.1 to 2.0 of a total of 5) and non-participant mothers (from a score of 1.0 to 1.6).

Among fathers too, significantly more reported in the endline survey than in the baseline survey that they favoured the provision of information about all five issues discussed. Increases were, however, more or less similar among participant and non-participant fathers. Thus, the percentages of fathers who agreed that daughters should be informed about menstruation before it occurs increased from 27 to 47 among participants and from 18 to 35 among non-participants. 
Table 4.4: Perceptions about parents' role in communicating non-sensitive and sensitive matters to adolescents expressed by participant and non-participant parents at baseline and endline

\begin{tabular}{|c|c|c|c|c|c|c|c|c|}
\hline & \multicolumn{4}{|c|}{ Mothers } & \multicolumn{4}{|c|}{ Fathers } \\
\hline & \multicolumn{2}{|c|}{ Non-participants } & \multicolumn{2}{|c|}{ Participants } & \multicolumn{2}{|c|}{ Non-participants } & \multicolumn{2}{|c|}{ Participants } \\
\hline & Baseline & Endline & Baseline & Endline & Baseline & Endline & Baseline & Endline \\
\hline Number of parents & \multicolumn{2}{|c|}{340} & \multicolumn{2}{|c|}{117} & \multicolumn{2}{|c|}{255} & \multicolumn{2}{|c|}{52} \\
\hline
\end{tabular}

Percent reporting that daughters should be given information on:

Money matters, e.g., spending and saving or family economic situation (before puberty, during adolescence)

Attraction between boys and girls (before puberty or during adolescence)

Bodily changes during puberty such as breast development, pubic hair growth, etc. (before puberty)

Menstruation (before puberty)

How pregnancy happens /sexual relationships between men and women (during adolescence before marriage)

Contraception (during adolescence before marriage)

Index of attitudes about the provision of information on sensitive various matters to adolescents (Range 0 to 5 )

Mean

\begin{tabular}{|c|c|c|c|c|c|c|c|}
\hline 99.1 & $100.0^{\sim}$ & 99.1 & 100.0 & 93.8 & $100.0^{* * *}$ & 95.9 & 100.0 \\
\hline 53.8 & $72.8^{* * *}$ & 57.5 & $81.1^{* * *}$ & 53.9 & $90.0^{* * *}$ & 67.8 & $90.3^{* * *}$ \\
\hline 13.4 & $28.5^{* * *}$ & 14.1 & $34.0^{* * *}$ & 20.8 & $37.6^{* * *}$ & 28.0 & $47.1^{* * *}$ \\
\hline 18.0 & $31.5^{* *}$ & 17.0 & $46.6^{* * *}$ & 18.1 & $34.5^{* * *}$ & 27.0 & $47.1^{* * *}$ \\
\hline 13.0 & $24.4^{\star \star *}$ & 9.3 & $35.8^{* * *}$ & 33.4 & $64.4^{* \star *}$ & 36.2 & $63.9^{* * *}$ \\
\hline 6.6 & $21.2^{* * *}$ & 6.7 & $28.8^{* \star *}$ & 25.5 & $56.1^{* * *}$ & 30.6 & $56.0^{\star \star *}$ \\
\hline 1.0 & $1.8^{* * *}$ & 1.0 & $2.3^{* * *}$ & 1.5 & $2.8^{* * *}$ & 1.9 & $3.0^{* * *}$ \\
\hline
\end{tabular}

Percent reporting that sons should be given information on:

Money matters, e.g., spending and saving or family economic situation (before puberty, during adolescence)

Attraction between boys and girls (before puberty or during adolescence)

Bodily changes during puberty such as voice change, pubic hair growth, facial hair growth, etc. (before puberty)

Nocturnal emission (before puberty)

How pregnancy happens /sexual relationships between men and women (during adolescence)

\begin{tabular}{llllllll}
99.8 & 100.0 & 99.1 & 100.0 & 98.3 & $100.0^{*}$ & 100.0 & 100.0 \\
59.0 & $71.4^{* * *}$ & 64.6 & $84.4^{* * *}$ & 61.5 & $89.8^{* * *}$ & 74.4 & $93.8^{* * *}$ \\
11.4 & $24.9^{* * *}$ & 14.7 & $27.6^{*}$ & 16.0 & $33.4^{* * *}$ & 23.0 & $44.1^{* * *}$ \\
6.3 & $10.4^{*}$ & 6.7 & 13.8 & 8.8 & $21.3^{* * *}$ & 6.3 & $28.9^{* * *}$ \\
10.6 & $28.5^{* * *}$ & 14.8 & $36.9^{* * *}$ & 37.0 & $68.8^{* * *}$ & 48.4 & $71.4^{* * *}$ \\
\hline
\end{tabular}

Cont'd on next page... 


\begin{tabular}{|c|c|c|c|c|c|c|c|c|}
\hline & \multicolumn{4}{|c|}{ Mothers } & \multicolumn{4}{|c|}{ Fathers } \\
\hline & \multicolumn{2}{|c|}{ Non-participants } & \multicolumn{2}{|c|}{ Participants } & \multicolumn{2}{|c|}{ Non-participants } & \multicolumn{2}{|c|}{ Participants } \\
\hline & Baseline & Endline & Baseline & Endline & Baseline & Endline & Baseline & Endline \\
\hline Number of parents & \multicolumn{2}{|c|}{340} & \multicolumn{2}{|c|}{117} & \multicolumn{2}{|c|}{255} & \multicolumn{2}{|c|}{52} \\
\hline $\begin{array}{l}\text { Contraception (during adolescence } \\
\text { before marriage) }\end{array}$ & 10.2 & $26.2^{* * *}$ & 9.0 & $36.2^{* * *}$ & 32.2 & $65.2^{* * *}$ & 44.2 & $69.3^{* * *}$ \\
\hline $\begin{array}{l}\text { Index of attitudes about provision } \\
\text { of information on sensitive } \\
\text { various matters to adolescents }\end{array}$ & & & & & & & & \\
\hline [Range 0 to 5] [Mean] & 1.0 & $1.6^{* * *}$ & 1.1 & $2.0^{* * *}$ & 1.6 & $2.8^{* * *}$ & 2.0 & $3.1^{* * *}$ \\
\hline
\end{tabular}

Note: $\sim p<=0.10,{ }^{*} p<=0.05,{ }^{* *} p<=0.01,{ }^{* *} p<=0.001$. Differences in the means between endline and baseline are based on paired t-tests.

Similarly, the percentages of fathers who agreed that sons should be informed about nocturnal emission before puberty increased from 6 to 29 among participants and 9 to 21 among non-participants. On the whole, as evident from the summary index, attitudes have become significantly more favourable with regard to informing daughters and sons among participant fathers (from a score of 1.9 to 3.0 for daughters and 2.0 to 3.1 for sons of a total of 5) as well as non-participant fathers (from a score of 1.5 to 2.8 for daughters and 1.6 to 2.8 for sons).

Figure 4.3 presents findings of the DiD models about attitudes toward the provision of information to sons and daughters in instances in which changes could be attributed to exposure to the intervention (non-significant changes are not presented). DiD estimates confirm once again that there was no effect of the intervention on fathers' attitudes. However, among mothers, attitudes about informing daughters about menstruation before its onset, informing adolescent daughters about pregnancy-related matters and, similarly, informing sons, during adolescence, about contraception were attributable to the intervention. Increases in the summary index of attitudes about the provision of information to daughters on sensitive matters among mothers exposed to the intervention were also attributable to exposure to the intervention. Indeed, findings may be interpreted to imply that 53 percent

Figure 4.3: Effects of exposure to the intervention programme on mothers' perceptions about parents' role in communicating sensitive matters to adolescents
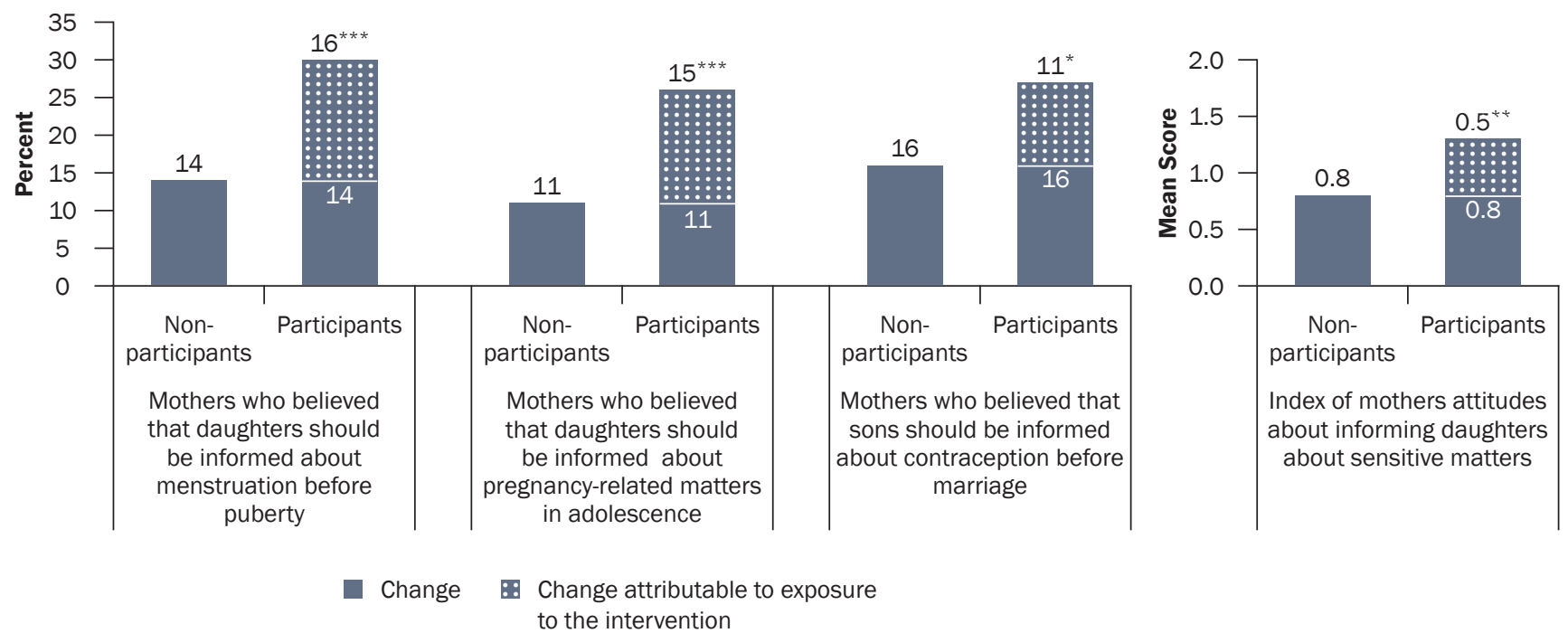

Note: $t$-test for DiD estimate $>0$ significant at ${ }^{*} p<=0.05,{ }^{* *} p<=0.01,{ }^{* *} p<=0.001$. Each bar represents change between baseline and endline. DiD estimate: Change among intervention participants minus change among non-participants. 
of the change in mothers' attitudes about informing daughters about menstruation before it occurs and 58 percent of the change in the attitudes of mothers about informing daughters during their adolescence about pregnancy could be attributed to the intervention. Similarly, 41 percent of the change in attitudes about informing sons about contraception could be attributed to the intervention. Among mothers, moreover, the DiD estimates suggest that a significant percentage (38 percent) of the change in the index of attitudes about the provision of information to daughters could be attributed to the intervention. In short, this section suggests that although attitudes had become more favourable among both participants and non-participants, the intervention did indeed result in changing some attitudes held by mothers about the importance of educating children-more consistently daughters than sons-at age-appropriate times about physical maturation and SRH matters. No such effect was observed for fathers.

\section{Effects of the intervention on socialisation practices and parent-child communication}

\section{Socialisation practices: findings from parents}

We measured the extent of changes in socialisation practices in two ways. First, in the endline survey, we asked mothers and fathers who had participated in the intervention to assess whether they felt that they shared a closer relationship with their sons and daughters at the time of the interview than prior to participating in the intervention, and we also posed the same question to non-participants, but, more generally and as compared with a year earlier. We recognise that questions were differently posed and therefore not entirely comparable, that the measure is subjective, and that corresponding questions were not asked at baseline comparisons. Our second measure explores changes over the time in mothers' and fathers' reports about whether they permitted their children to exercise agency in their everyday life, whether they disciplined their children by using corporal punishment and whether they regularly interacted with their sons and daughters for both group of parents. Findings are presented in Figure 4.4 and Table 4.5.

Reports from the endline survey show that perceived closeness with children had improved considerably and that significantly more participant than non-participant mothers and fathers reported that they shared a closer relationship with their children at the time of the endline interview than they had earlier (prior to participating in the intervention for participants and a year earlier for non-participants). Among participant mothers, 73 percent and 61 percent reported a closer relationship with their daughters and sons, respectively, prior to the intervention, compared with 44 percent and 34 percent of non-participant mothers over the previous year (Figure 4.4).

Figure 4.4: Self-assessment of relationship with children: Percentage of mothers and fathers who reported in the endline survey a closer relationship with children than prior to participation in the intervention (participants)/a year earlier (non-participants)

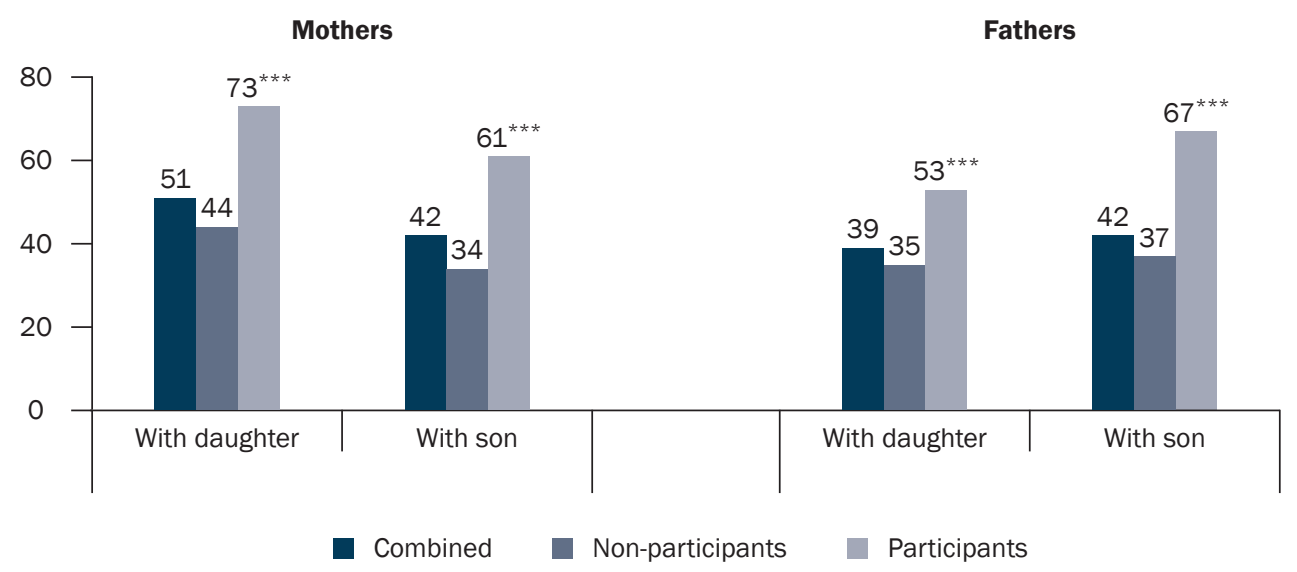

Note: ${ }^{* *} p<=0.001$. Independent samples t-test showing the significant differences in the means between participants and non-participants. 
Table 4.5: Socialisation practices reported by participant and non-participant parents at baseline and endline

\begin{tabular}{|c|c|c|c|c|c|c|c|c|}
\hline & \multicolumn{4}{|c|}{ Mothers } & \multicolumn{4}{|c|}{ Fathers } \\
\hline & \multicolumn{2}{|c|}{ Non-participants } & \multicolumn{2}{|c|}{ Participants } & \multicolumn{2}{|c|}{ Non-participants } & \multicolumn{2}{|c|}{ Participants } \\
\hline & Baseline & Endline & Baseline & Endline & Baseline & Endline & Baseline & Endline \\
\hline \multicolumn{9}{|c|}{ Daughter } \\
\hline $\begin{array}{l}\text { Number of parents with } \\
\text { daughters }\end{array}$ & \multicolumn{2}{|c|}{200} & \multicolumn{2}{|c|}{66} & \multicolumn{2}{|c|}{120} & \multicolumn{2}{|c|}{29} \\
\hline \multicolumn{9}{|c|}{ Encouragement of agency among children } \\
\hline \multicolumn{9}{|l|}{$\begin{array}{l}\text { Encourages daughters to exercise } \\
\text { agency in matters relating to }\end{array}$} \\
\hline adolescents' life & 30.2 & $53.9^{* * *}$ & 28.8 & $54.3^{* *}$ & 24.4 & $42.7^{* * *}$ & 19.5 & $49.4^{* *}$ \\
\hline \multicolumn{9}{|c|}{ Perpetration of violence against children } \\
\hline $\begin{array}{l}\text { Had beaten/slapped daughters } \\
\text { the past six months }\end{array}$ & 33.9 & $22.7^{\star \star}$ & 23.4 & 20.6 & 10.1 & 5.5 & 3.7 & 3.9 \\
\hline \multicolumn{9}{|l|}{ Interaction with children } \\
\hline \multicolumn{9}{|l|}{$\begin{array}{l}\text { In the past one month, spent time } \\
\text { regularly talking/joking with their }\end{array}$} \\
\hline daughter & 89.1 & 92.3 & 91.5 & 96.8 & 83.6 & 76.8 & 70.4 & 75.9 \\
\hline \multicolumn{9}{|l|}{$\begin{array}{l}\text { Played/had fun with their } \\
\text { daughter and taken her to a }\end{array}$} \\
\hline picnic/mela/tamasha/cinema & 25.7 & 26.7 & 26.0 & 36.5 & 5.6 & 2.0 & 11.8 & 18.9 \\
\hline \multicolumn{9}{|c|}{ Son } \\
\hline \multicolumn{9}{|l|}{$\begin{array}{l}\text { Encouragement of agency } \\
\text { among children }\end{array}$} \\
\hline $\begin{array}{l}\text { Encourages sons to exercise } \\
\text { agency in matters relating to }\end{array}$ & 60.8 & $83.4^{* * *}$ & 54.5 & $83.7^{* * *}$ & 71.8 & $87.4^{* * *}$ & 61.9 & $86.0^{*}$ \\
\hline \multicolumn{9}{|c|}{ Perpetration of violence against children } \\
\hline $\begin{array}{l}\text { Had beaten/slapped sons in th } \\
\text { past six months }\end{array}$ & 35.5 & $24.0^{* *}$ & 34.5 & $24.4^{\sim}$ & 31.9 & $19.1^{* *}$ & 33.2 & 27.5 \\
\hline \multicolumn{9}{|l|}{ Interaction with children } \\
\hline $\begin{array}{l}\text { In the past one month, spent ti } \\
\text { regularly talking/joking with the }\end{array}$ & & & & & & & & \\
\hline sons & 83.6 & 86.1 & 88.7 & 83.9 & 88.0 & 83.1 & 87.7 & 83.4 \\
\hline $\begin{array}{l}\text { Played/had fun with their sons } \\
\text { and taken him to a picnic/mela } \\
\text { tamasha/cinema }\end{array}$ & 16.7 & 12.6 & 13.3 & 14.8 & 9.0 & 7.3 & 16.1 & 9.2 \\
\hline
\end{tabular}

Note: $\sim p<=0.10,{ }^{*} p<=0.05,{ }^{* *} p<=0.01,{ }^{* *} p<=0.001$. Differences in the means between endline and baseline are based on paired t-tests.

Among fathers, percentages who reported an improvement in their relationship with their daughters and sons, respectively, were 53 and 67 . Just as for mothers, significantly more fathers who had participated in the intervention reported a closer relationship than did those who had not participated. 
Our more objective indicators tell a different story. Findings are presented in Table 4.5. They suggest that irrespective of their participation status, mothers and fathers alike were far less likely to report that they allowed their daughters to make decisions and move around freely than they were to report so about their sons, and this practice persisted at the time of both the baseline survey and the endline survey. There were significant increases, however, among both participant and non-participant groups in the percentages of mothers and fathers who permitted their children to exercise autonomy at the time of the endline survey. In the baseline survey, percentages of participant and non-participant mothers who encouraged the exercise of agency of daughters were 29 and 30, respectively, and the corresponding percentages of fathers were 20 and 24. By the time of the endline survey, the percentages had increased to 54 among both groups of mothers and to 49 and 43 for participant and non-participant fathers, respectively. Correspondingly, percentages of parents who allowed their sons to display agency in these respects increased from 55 and 61 in the baseline survey to 84 and 83 in the endline survey among participant and non-participant mothers, respectively, and from 62 and72 in the baseline survey to 86 and 87 in the endline survey among participant and non-participant fathers, respectively.

In the baseline survey, among participant mothers, 35 percent reported that they had slapped or beaten their son and 23 percent reported that they had slapped or beaten their daughter in the six months preceding the interview, compared with 36 percent reporting thus for sons and 34 percent reporting thus for daughters among nonparticipant mothers. The percentages of participant and non-participant mothers reporting violence against their sons did indeed decline significantly between the baseline and endline surveys, from 35-36 percent to 24 percent. For daughters, non-participant mothers reported significant decline over the time (34 percent to 23 percent) and participant mothers reported modest declines (from 23 percent to 21 percent). Among fathers, there was a decline in the percentage with regard to violence against sons among non-participants (32 percent to 19 percent), but not among participants. Furthermore, very few (10 percent or less) reported perpetrating violence on a daughter in both of the surveys. Given the secular decline in reported perpetration of violence against sons in both groups, and the greater decline in reported perpetration of violence by mothers against daughters and fathers against sons among non-participants than participants, it is difficult to attribute the change among participant mothers and fathers to the intervention.

Finally, with regard to interaction with sons and daughters, while large proportions of mothers and fathers did indeed report that they spent time chatting and joking with their children in the month preceding the interview, far fewer reported "doing something fun" with their children or taking their children on an outing in the six months preceding the interview. Large proportions of mothers, irrespective of participation status, reported spending time chatting and joking with their daughters (89-92 percent) and their sons (84-89 percent) in the baseline survey, with percentages remaining similar in the endline survey for both non-participants and participants (92-97 percent for daughters and 84-86 percent for sons). Correspondingly, in the baseline survey, 88 percent from both groups of fathers reported that they spent time chatting and joking with their sons, and 84 percent and 70 percent of fathers (non-participants and participants fathers, respectively) reported having done so with their daughters. There was little change by the time of the endline survey ( 83 percent for both groups of fathers with regard to sons and 77 percent for nonparticipant fathers and 76 percent for participant fathers with regard to daughters).

Considerably fewer mothers and fathers reported "doing something fun" with their children or taking their children on an outing. Mothers were far more likely to report such interaction with their daughters (26 percent each of participant and non-participant mothers) than with sons (13 percent and 17 percent, respectively) in the baseline survey, with percentages so reporting increasing considerably among participant mothers (to 37 percent) by the endline survey, but remaining virtually unchanged among non-participant mothers (27 percent in the endline survey). Reports of fathers were inconsistent: those who had participated in the intervention were more likely to report such interaction with their daughters in the endline survey than in the baseline survey (19 percent versus 12 percent), but less likely to so report regarding their sons ( 9 percent versus 16 percent); changes among non-participant fathers were negligible.

Findings of the DiD model (not shown) suggest that, notwithstanding parents' self-perceived closer relations with their children over the period of the intervention, there was no evidence of an independent effect of participation in the intervention on these practices. 


\section{Parent-child communication as reported by parents}

We measured the extent to which communication between parents and adolescents had been enhanced over the period between the baseline and the endline survey in two ways. First, we asked participant parents to assess, in the endline survey, whether they felt more comfortable about communicating on SRH matters with their sons and daughters than they had prior to participating in the intervention. We also asked non-participant parents at the time of the endline survey, whether, compared to a year earlier, they felt more comfortable discussing SRH matters with their children. We recognise that questions were differently posed and therefore not entirely comparable, that the measure is subjective and that corresponding questions were not asked at baseline comparisons. Our second measure drew on parents' reports about whether they communicated on both general and SRH matters with their sons and daughters, and we assessed changes in their responses over the time from the baseline to the endline survey. Findings are presented in Figure 4.5 and Table 4.6.

Figure 4.5: Self-assessment of communication with children: Percentage of mothers and fathers who reported in the endline survey greater ease in communicating with their adolescent children about SRH matters than prior to participation in the intervention (participants)/a year earlier (non-participants)

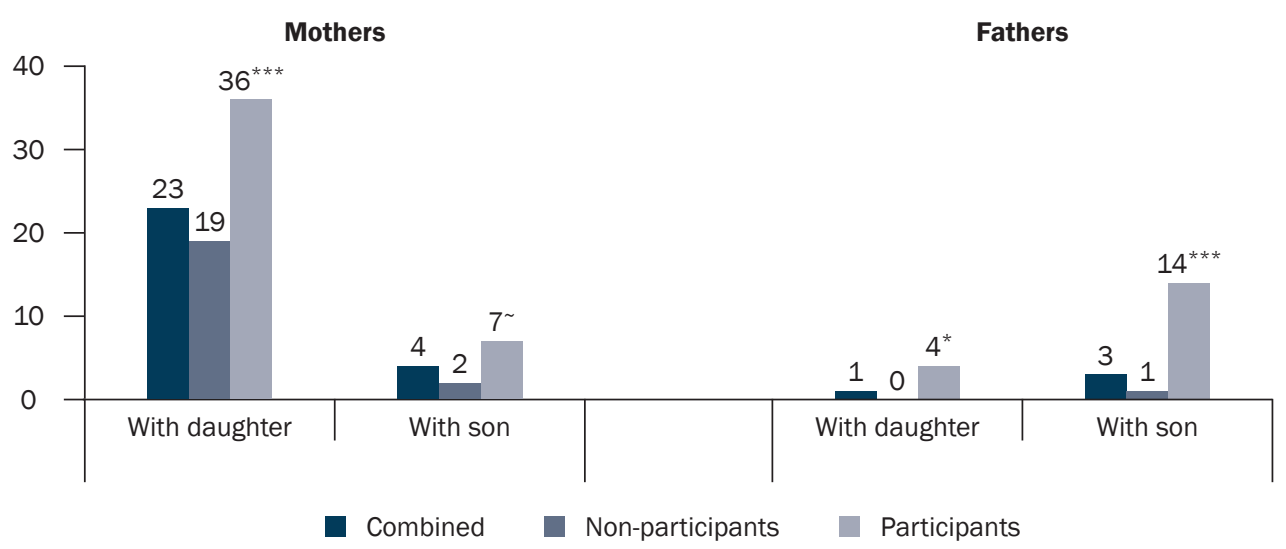

Note: $\sim p<=0.10,{ }^{*} p<=0.05,{ }^{* *} p<=0.001$. Independent samples t-test showing the significant differences in the means between participants and non-participants.

With regard to self-assessed changes in feelings of ease about communicating about sensitive matters, as seen in Figure 4.5, many mothers-almost one quarter-reported that they felt more comfortable than a year earlier about discussing SRH matters with their daughters; indeed, significantly more participant than non-participant mothers (36 percent versus 19 percent) so reported. In contrast, just 4 percent of all mothers felt more comfortable about discussing similar matters with their sons, though participant mothers were more likely than non-participant mothers to report greater comfort ( 7 percent versus 2 percent). In contrast, hardly any father reported feeling more comfortable about discussing SRH matters at the time of the endline interview than earlier, but differences between participant and non-participant fathers were significant (14 percent and 1 percent, respectively, with regard to sons; 4 percent and 0 percent, respectively, with regard to daughters).

As clear from Table 4.6, in the baseline survey, the large majority of mothers reported that they had discussed family problems or money matters with their sons (87 percent of non-participant mothers and 96 percent of participant mothers) and daughters (82 percent of non-participant mothers and 87 percent of participant mothers). These percentages remained by and large similar at the time of the endline survey (with sons, 90 percent for nonparticipant mothers and 92 percent for participant mothers; and with daughters, 89 percent for non-participant and 91percent for participant mothers). While changes among mothers were evident, fewer fathers than mothers reported communication with children on family problems or money matters and there was no change perceptible in fathers' reports over time.

That communication with both sons and daughters about sensitive SRH matters was rare was evident from both the baseline survey and the endline survey. Indeed, communication about pregnancy or contraception with sons and daughters was not at all reported or reported by 1-2 percent of mothers and 0-3 percent of fathers in both surveys, irrespective of participation status. Somewhat more mothers had discussed HIV/AIDS with their sons and 
Table 4.6: Parent-child communication: Percentage of participant and non-participant parents who discussed nonsensitive and sensitive matters with their adolescent children at baseline and endline

\begin{tabular}{|c|c|c|c|c|c|c|c|c|}
\hline & \multicolumn{4}{|c|}{ Mothers } & \multicolumn{4}{|c|}{ Fathers } \\
\hline & \multicolumn{2}{|c|}{ Non-participants } & \multicolumn{2}{|c|}{ Participants } & \multicolumn{2}{|c|}{ Non-participants } & \multicolumn{2}{|c|}{ Participants } \\
\hline & Baseline & Endline & Baseline & Endline & Baseline & Endline & Baseline & Endline \\
\hline \multicolumn{9}{|c|}{ Daughter } \\
\hline $\begin{array}{l}\text { Number of parents with } \\
\text { daughters }\end{array}$ & \multicolumn{2}{|c|}{200} & \multicolumn{2}{|c|}{66} & \multicolumn{2}{|c|}{120} & \multicolumn{2}{|c|}{29} \\
\hline \multicolumn{9}{|l|}{ Non-sensitive matters } \\
\hline $\begin{array}{l}\text { Any problems faced in th } \\
\text { or about money matters }\end{array}$ & 81.9 & $89.3^{*}$ & 87.1 & 90.9 & 59.2 & 60.3 & 61.2 & 52.8 \\
\hline \multicolumn{9}{|l|}{ Sensitive matters } \\
\hline Menstruation & 66.4 & $76.3^{* * *}$ & 63.2 & $73.4^{* *}$ & 0.0 & 0.0 & 0.0 & 0.0 \\
\hline How pregnancy occurs & 1.2 & 0.6 & 0.9 & 1.7 & 0.0 & 0.0 & 0.0 & 0.0 \\
\hline Contraception & 0.6 & 1.9 & 0.0 & 0.9 & 0.0 & 0.0 & 0.0 & 0.0 \\
\hline HIV/AIDS & 4.7 & 4.1 & 9.5 & 16.8 & 1.0 & 0.0 & 3.9 & 3.9 \\
\hline \multicolumn{9}{|c|}{ Son } \\
\hline \multicolumn{9}{|l|}{ Number of parents with } \\
\hline \multicolumn{9}{|l|}{ Non-sensitive matters } \\
\hline $\begin{array}{l}\text { Any problems faced in th } \\
\text { or about money matters }\end{array}$ & 86.7 & 89.5 & 95.7 & 92.0 & 61.7 & 69.3 & 72.1 & 69.6 \\
\hline \multicolumn{9}{|l|}{ Sensitive matters } \\
\hline Nocturnal emission & 0.0 & $1.8^{\sim}$ & 0.0 & 1.7 & 1.1 & 1.4 & 3.3 & 8.4 \\
\hline How pregnancy occurs & 0.0 & 0.6 & 0.0 & 0.0 & 0.0 & 0.0 & 3.3 & 0.0 \\
\hline Contraception & 0.0 & 0.0 & 0.0 & 0.0 & 0.0 & 0.0 & 3.3 & 5.1 \\
\hline HIV/AIDS & 3.3 & 5.3 & 2.8 & $8.1^{\sim}$ & 3.3 & 2.9 & 3.3 & 8.4 \\
\hline
\end{tabular}

Note: $\sim p<=0.10,{ }^{*} p<=0.05,{ }^{* *} p<=0.01,{ }^{* *} p<=0.001$. Differences in the means between endline and baseline are based on paired t-tests.

daughters and increases in the percentages of mothers discussing HIV/AIDS over the period of the intervention were evident among participant but not non-participant mothers. Percentages of mothers who had discussed HIV/ AIDS increased (from baseline to endline survey) among participant mothers from 3 percent to 8 percent with regard to communication with sons and from 10 percent to 17 percent with regard to communication with daughters, compared with hardly any change among non-participant mothers (from 3 percent to 5 percent and from 5 percent to 4 percent for sons and daughters, respectively). In contrast, hardly any fathers had discussed HIV/AIDS with their sons and daughters in the baseline survey (1-4 percent), and percentages increased mildly for both groups of fathers (3-8 percent) in the endline survey.

Puberty-related topics were also rarely discussed. Indeed, neither fathers nor mothers had discussed nocturnal emission with their sons in the baseline or the endline survey, and not a single father had discussed menstruation with his daughter. Significant increases in communication were observed only in the case of communication about menstruation by mothers with their daughters. About 10 percent more mothers reported discussing menstruation with their daughters in the endline than the baseline survey (63 percent in the baseline survey to 73 percent in the endline survey among participants; 66 percent in the baseline survey to 76 percent in the endline survey among non-participants); this increase may well have corresponded with more daughters reaching menarche during the 
period between the baseline and the endline survey. Both the baseline survey and endline survey show, however, that the content of the communication was restricted to the mechanics and dos and don'ts of menstruation-use of a clean cloth, staying away from the temple or kitchen - rather than its underlying meaning.

Although many more participant than non-participant mothers and fathers reported that they felt more comfortable at the time of the endline survey than earlier about talking to their children about sensitive matters, the reality was quite different. Few parents reported improvements in communication with their children about sensitive matters, and findings from the DiD model (not shown) confirm that exposure to the intervention did not affect parent-child communication about sensitive matters.

\section{Socialisation patterns and communication with parents as reported by adolescents}

Adolescents' reports corroborate those of parents, as evident from Table 4.7a. Between 96 percent and 100 percent of sons reported they were permitted to visit various places outside the home unescorted, and just 75 percent to 87 percent of daughters so reported, with differences in the percentages of this measure between the baseline and the endline survey being negligible. Sons were significantly less likely in the endline than the baseline survey to report that their father and mother had beaten them, and declines were particularly notable among those whose parents had participated in the intervention (from 63 percent of sons reporting violence from both fathers and mothers in the baseline survey to 40 percent reporting violence from fathers and 46 percent reporting violence from mothers in the endline survey). Daughters whose parents had participated in the intervention reported no change in experiences of violence perpetrated by their mother or father; those whose parents had notparticipated, did, however report significant declines in experience of violence perpetrated by their parents. Finally, interaction with parents, for the most part, showed no change in its percentages in the baseline and the endline survey; however, daughtersparticularly those whose parents had participated in the intervention-were significantly more likely in the endline than the baseline survey to report interaction with their mother (from 26 percent in the baseline survey to 52 percent in the endline survey, and from 26 percent in the baseline survey to 36 percent in the endline survey for those whose mother had not participated). Very few sons, in contrast, reported interaction with their mother and very few sons and daughters reported interaction with their father in both surveys and irrespective of participation status of fathers (6-13 percent for sons and 11-16 percent for daughters).

Adolescents' reports of parent-child communication about both general matters and matters relating to SRH (Table 4.7b) did not change for most topics over the course of the intervention, and changes, where they occurred, were inconsistent. Large proportions of adolescent daughters from both groups reported communication about family and money matters with their mother in both surveys ( 84 percent in the baseline survey and 90 percent each in the endline survey). Considerably fewer sons reported such communication in both the baseline survey and the endline survey (60-74 percent and 72-73, respectively). Similarly, fewer daughters and sons reported such communication with their father (59-62percent and 66-75 percent among daughters in the baseline and the endline survey, respectively; 59-68 percent and 71-76 percent, respectively, among sons). Changes over time were negligible (except among sons of non-participants who reported significant increases in communication with both parents). Communication about sensitive physical maturation and SRH matters were negligible across the board. Indeed, in most cases, not a single adolescent reported that a parent had discussed these matters with them. The only exception, as noted by mothers as well, was communication between mothers and daughters about menstruation, which increased from 85 percent to 92 percent of daughters whose mothers were non-participants and from 82 to 94 percent of daughters whose mothers were participants in the intervention (from the baseline to the endline survey).

On the whole, socialisation patterns, as reported by sons and daughters, had not changed over the period of the intervention, with a few exceptions, as discussed above. Findings from the DiD model, presented in Figure 4.6 confirm that parental exposure to the intervention had an effect on just sons' experience of violence perpetrated by their mother and father, respectively, in the six months preceding the interview, and daughters' interaction with their mother (non-significant effects are not shown). Indeed, as seen in Figure 4.6, 83 percent and 67 percent of the decline in violence perpetrated on sons by their father and mother, respectively, and 62 percent of the increase in daughters' interaction with their mother could be attributed to the intervention. In contrast, no such change was observed for parent-child communication. Indeed, findings related to communication strongly corroborate the findings of mothers and fathers and emphasise that participation in the intervention had not translated into changes in behaviour over the year between the baseline and the endline survey. 
Figure 4.6: Effects of parental exposure to the intervention programme on indicators of sons' and daughters' socialisation experiences, as reported by adolescent boys and girls

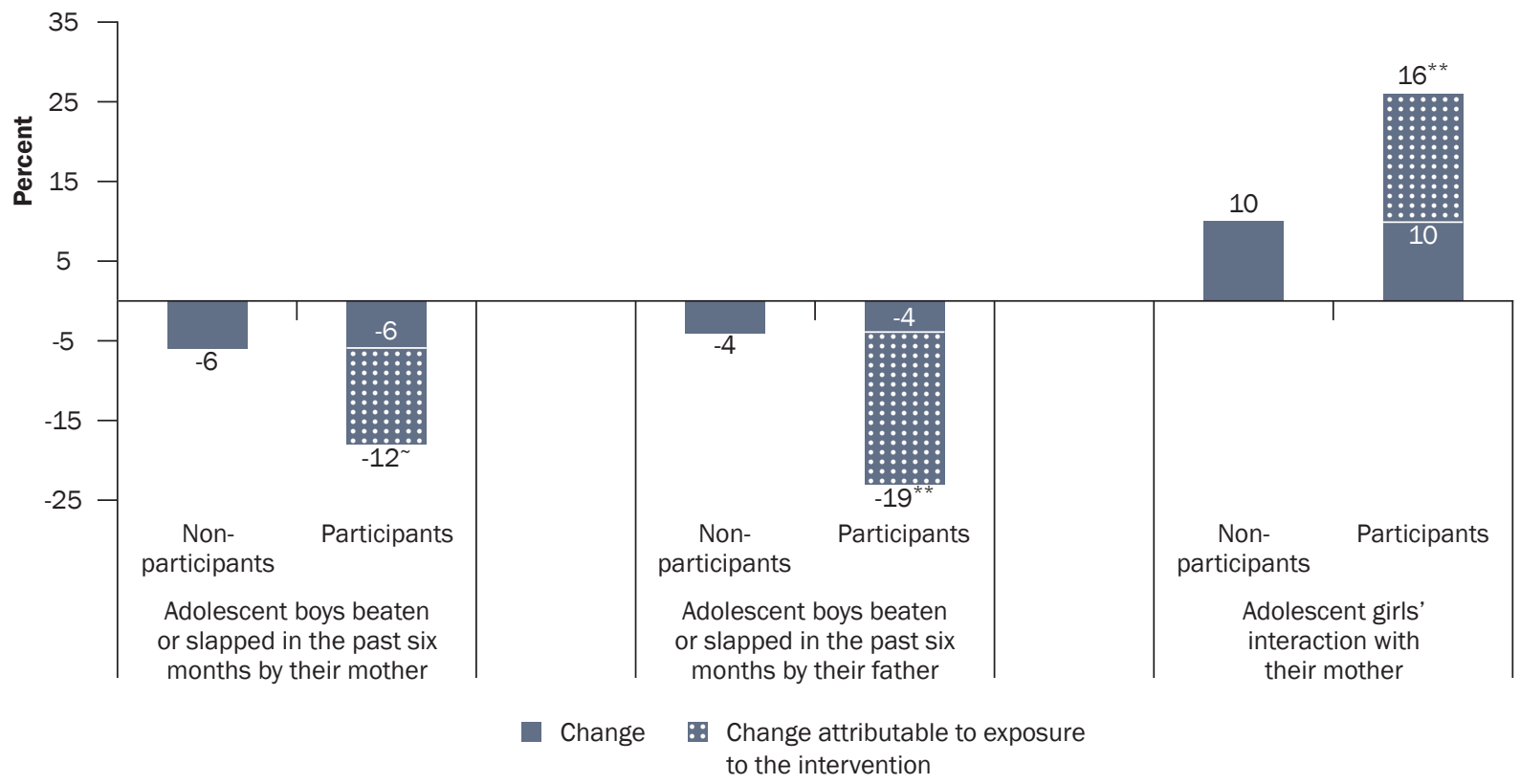

Note: $t$-test for DiD estimate $>0$ significant at $\sim p<=0.10,{ }^{* *} p<=0.01$. Each bar represents change between baseline and endline. DiD estimate: Change among intervention participants minus change among non-participants.

Table 4.7a: Socialisation experiences reported by adolescent children of participant and non-participant parents at baseline and endline

\begin{tabular}{|c|c|c|c|c|c|c|c|c|}
\hline & \multicolumn{4}{|c|}{ Sons } & \multicolumn{4}{|c|}{ Daughters } \\
\hline & \multicolumn{2}{|c|}{ Non-participants } & \multicolumn{2}{|c|}{ Participants } & \multicolumn{2}{|c|}{ Non-participants } & \multicolumn{2}{|c|}{ Participants } \\
\hline & Baseline & Endline & Baseline & Endline & Baseline & Endline & Baseline & Endline \\
\hline \multicolumn{9}{|c|}{ Mother } \\
\hline $\begin{array}{l}\text { Number of adolescents } \\
\text { co-residing with mother }\end{array}$ & \multicolumn{2}{|c|}{283} & \multicolumn{2}{|c|}{81} & \multicolumn{2}{|c|}{254} & \multicolumn{2}{|c|}{66} \\
\hline $\begin{array}{l}\text { Adolescent permitted by mother } \\
\text { to go out alone to a nearby shor } \\
\text { religious place/friend's home }\end{array}$ & 96.3 & $99.5^{\star}$ & 98.9 & 100 & 77.1 & 80.9 & 85.5 & 83.6 \\
\hline $\begin{array}{l}\text { Adolescent beaten/slapped by } \\
\text { mother in the past six months }\end{array}$ & 48 & $42.2^{\sim}$ & 62.9 & $45.5^{* *}$ & 32.9 & $22.4^{* *}$ & 27.2 & 26.3 \\
\hline Interaction with mother & 6.1 & $11.7^{*}$ & 15.3 & 15.6 & 26.2 & $35.7^{\star}$ & 25.8 & $51.6^{* *}$ \\
\hline \multicolumn{9}{|c|}{ Father } \\
\hline $\begin{array}{l}\text { Number of adolescents } \\
\text { co-residing with father }\end{array}$ & \multicolumn{2}{|c|}{266} & \multicolumn{2}{|c|}{73} & \multicolumn{2}{|c|}{208} & \multicolumn{2}{|c|}{54} \\
\hline $\begin{array}{l}\text { Adolescent permitted by father } \\
\text { go out alone to a nearby shop/ } \\
\text { religious place/friend's home }\end{array}$ & 96.5 & 96.9 & 97.5 & 100 & 75.1 & 79.2 & 82.6 & 86.5 \\
\hline $\begin{array}{l}\text { Adolescent beaten/slapped by } \\
\text { father in the past six months }\end{array}$ & 43.5 & 40 & 62.9 & $40.4^{* *}$ & 9.6 & $3.3^{* *}$ & 11.1 & 10 \\
\hline Interaction with father & 5.9 & 8.1 & 13.1 & 9.5 & 11.1 & 10.7 & 14.3 & 16.3 \\
\hline
\end{tabular}

Note: $\sim p<=0.10,{ }^{*} p<=0.05,{ }^{* *} p<=0.01$. Differences in the means between endline and baseline are based on paired t-tests. 
Table 4.7b: Communication with parents: Percentage of adolescent children of participant and non-participant parents who discussed non-sensitive and sensitive matters with their parents at baseline and endline

\begin{tabular}{|c|c|c|c|c|c|c|c|c|}
\hline & \multicolumn{4}{|c|}{ Sons } & \multicolumn{4}{|c|}{ Daughters } \\
\hline & \multicolumn{2}{|c|}{ Non-participants } & \multicolumn{2}{|c|}{ Participants } & \multicolumn{2}{|c|}{ Non-participants } & \multicolumn{2}{|c|}{ Participants } \\
\hline & Baseline & Endline & Baseline & Endline & Baseline & Endline & Baseline & Endline \\
\hline \multicolumn{9}{|c|}{ Mother } \\
\hline $\begin{array}{l}\text { Number of adolescents } \\
\text { co-residing with mother }\end{array}$ & \multicolumn{2}{|c|}{283} & \multicolumn{2}{|c|}{81} & \multicolumn{2}{|c|}{254} & \multicolumn{2}{|c|}{66} \\
\hline $\begin{array}{l}\text { Adolescent ever discusse } \\
\text { family or money problem } \\
\text { with mother }\end{array}$ & 59.9 & $71.7^{\star \star \star}$ & 74.3 & 72.9 & 84.3 & $89.5^{\sim}$ & 84.3 & 90.2 \\
\hline $\begin{array}{l}\text { Communicated with } \\
\text { mother about physical } \\
\text { maturation and SRH ma } \\
\text { (adolescents aged 15-1 }\end{array}$ & & & & & & & & \\
\hline Nocturnal emission (for $\mathrm{b}$ & & & & & & & & \\
\hline Menstruation (for girls) & 0.0 & 0.0 & 0.0 & 1.9 & 85.3 & $91.5^{\star *}$ & 82.4 & $94.1^{\sim}$ \\
\hline How pregnancy occurs & 0.0 & 0.0 & 0.0 & 0.0 & 0.9 & 2.4 & 0.0 & 0.0 \\
\hline Contraception & 0.0 & 0.0 & 0.0 & 0.0 & 0.5 & 2.5 & 0.0 & 1.2 \\
\hline HIV/AIDS & 0.0 & 0.0 & 0.0 & 0.0 & 4 & 9.4 & 0.0 & 3.5 \\
\hline \multicolumn{9}{|c|}{ Father } \\
\hline $\begin{array}{l}\text { Number of adolescents } \\
\text { co-residing with father }\end{array}$ & \multicolumn{2}{|c|}{266} & \multicolumn{2}{|c|}{73} & \multicolumn{2}{|c|}{208} & \multicolumn{2}{|c|}{54} \\
\hline $\begin{array}{l}\text { Adolescent ever discusse } \\
\text { family or money problem } \\
\text { with father }\end{array}$ & 59 & $71.3^{* * \star}$ & 67.7 & 76.1 & 58.7 & 66 & 62.1 & 75 \\
\hline $\begin{array}{l}\text { Communicated with } \\
\text { father about physical } \\
\text { maturation and SRH ma } \\
\text { (adolescents aged 15-1 }\end{array}$ & & & & & & & & \\
\hline Nocturnal emission (for $\mathrm{b}$ & & & & & & & & \\
\hline Menstruation (for girls) & 5.2 & 5.2 & 0.0 & 0.0 & 0.0 & 0.0 & 0.0 & 0.0 \\
\hline How pregnancy occurs & 5.2 & 5.2 & 0.0 & 0.0 & 0.0 & 0.0 & 0.0 & 0.0 \\
\hline Contraception & 5.2 & 5.2 & 0.0 & 0.0 & 0.0 & 0.0 & 0.0 & 0.0 \\
\hline HIV/AIDS & 3.1 & 3.1 & 0.0 & 0.0 & 4.9 & 4.9 & 0.0 & 0.0 \\
\hline
\end{tabular}

Note: $\sim p<=0.10,{ }^{*} p<=0.05,{ }^{* *} p<=0.01,{ }^{* *} p<=0.001$. Differences in the means between endline and baseline are based on paired t-tests.

\section{Limitations}

The results of the intervention were indeed disappointing and have shown that the intervention did not have a consistent effect, particularly among fathers, in changing their awareness, and attitudes or their socialisation and communication practices. The several challenges discussed earlier have clearly contributed to this limited effect. Also, not all intervention participants placed priority on regular attendance, and those who attended did not always value intervention messages especially those that involved communicating with children about SRH matters and those that called for greater exercise of agency among girls. 
At the same time, we note that both those exposed to the intervention and those who were not so exposed were not entirely independent of each other, and that the effect of the intervention may well have reached non-participants, albeit indirectly. In other words, some of the observed increases in outcome indicators among non-participants may not be entirely independent of the intervention. It appears, for example, that our intervention resulted in considerable interest among frontline workers. In many villages, sessions were held at anganwadi centres and ASHAs (Accredited Social Health Activists), anganwadi workers and ANMs (Auxillary Nurse Midwives) occasionally did attend some sessions. They may then have conveyed what they had learned across the villages they serve, thereby increasing awareness of non-participant mothers. Other community members, likewise, observed sessions partly and may have absorbed their content. It is also likely that participant mothers had discussed new ideas learned during the intervention sessions with non-participants. Trainers themselves were drawn from the local communities and may have discussed session content with non-participants.

\section{Summary}

In general, findings show that the effects of the intervention on parents' knowledge and attitudes were mixed and gendered. Positive effects of the intervention were observed with respect to such indicators as parental awareness of SRH matters, particularly those related to in-depth awareness of condoms and awareness of HIV/AIDS and other STIs. Similarly, parental attitudes had become more favourable to involving children in decisions about their own lives and informing children about sexual and reproductive matters. At the same time, findings show that the positive effects that the exposure to the intervention had on raising parental awareness of sexual and reproductive matters were observed in just a few instances-in-depth awareness of condoms and awareness about HIV/AIDS among mothers; awareness about pregnancy-related matters and emergency contraception among fathers; and mothers' attitudes about involving sons and daughters in the choice of marriage partner and about communicating on various sensitive matters with their daughters and, to a lesser extent, sons. Findings showed no effects on other issues, including parental awareness of other contraceptives, physical maturation issues, legal age for marriage and sex and pregnancy matters. Similarly, no effects attributable to exposure to the intervention were observed with regard to parents' gender-role attitudes. Moreover, where positive effects of exposure to the intervention were observed, they were more likely to have been observed among mothers than fathers.

With regard to socialisation practices or communication with their children, although there were some positive effects, the intervention fell short of changing mother's and fathers' socialisation practices or communication with their children. Socialisation practices remained gendered, and communication about sensitive SRH matters was rare as was evident from both the baseline survey responses and the endline survey responses with regard to both sons and daughters and among mothers and fathers who had participated in the intervention and those who had not. Indeed, exposure to the intervention appeared to have no effect on changing socialisation practices of mothers or fathers or their communication experiences. Thus, communication about nocturnal emission with sons and about pregnancy or contraception with sons and daughters was not at all reported or reported by only 1-3 percent of mothers and fathers in both the surveys, irrespective of participation status. Findings underscore huge challenges in breaking down strongly held traditional norms and in translating mothers' newly gained knowledge and favourable attitudes into practice.

Adolescent sons and daughters by and large reiterated the reports of their parents. Sons were significantly less likely in the endline than the baseline survey to report that their father and mother had beaten them, and declines were particularly notable among those whose parents had participated in the intervention. Interaction with parents was, for the most part, limited, as seen in both the baseline survey and the endline survey. However, significantly more daughters in the endline survey than the baseline survey reported interaction with their mother. On the whole, parents' exposure to the intervention had some effect on sons' reports of declines in the experience of violence perpetrated by their mother and father, and daughters' reports of interaction with their mother.

Parent-child communication, as reported by sons and daughters, did not change over the course of the intervention. Indeed, communication about sensitive physical maturation and SRH matters was negligible across the board, and on many topics-pregnancy, contraception, nocturnal emission-hardly any adolescent reported that a parent had communicated on these matters with them. There was, thus, no indication of change in the period between the baseline and the endline survey. 
The results of this intervention were indeed disappointing and have shown that it did not have a consistent effect, particularly among fathers, in changing their awareness and attitudes or their socialisation and communication practices. The several challenges discussed earlier have clearly contributed to this limited effect. Indeed, programme implementers experienced considerable difficulty in changing gendered and hierarchical norms and practices with regard to socialisation of and communication with children. Also, not all intervention participants placed priority on regular attendance, and those who attended did not always value intervention messages especially those that involved communicating with children about SRH matters and those that called for greater exercise of agency among daughters. At the same time, we note that both those exposed to the intervention and those who were not so exposed were not entirely independent of each other, and that the effect of the intervention may well have reached non-participants, albeit indirectly. 


\section{Chapter 5 \\ Summary and recommendations}

This chapter summarises the major findings of the project with regard to the acceptability and effectiveness of the intervention that was intended to improve parent-child interaction and communication. The chapter also highlights lessons learnt for programme implementation, sustainability and up-scaling.

\section{Summary}

This project was undertaken by the Population Council with CEDPA India as partner to assess the extent to which an intervention focused on developing parenting skills, in general, and on enabling parents to overcome obstacles in communicating with their adolescent children about SRH matters, in particular, succeeded in breaking down hierarchical relations between parents and children and enhancing parent-child communication about physical maturation and SRH matters. The intervention was developed on curriculums that were used in two projectsImproving the communication between parents and adolescent in reproductive health and HIV/AIDS project, implemented by CEDPA and the Population Council in Senegal (Diop and Diagne, 2008), and Better Life Options programme, intended to empower adolescents, transform gender norms and encourage child-parent communication from adolescents' perspective, implemented by CEDPA (CEDPA, 2000); these were modified to reflect the Indian context and the parental perspective, respectively.

The intervention, designed for implementation over a five-month period, was delivered over a period of approximately nine months owing to the need for rescheduling of sessions among mothers and fathers of boys and girls aged 13-17 in one block of rural Arrah (Bhojpur district) of Bihar. The intervention included a group-based learning programme for mothers and fathers, respectively, which entailed delivering a 16-session curriculum among them. The themes of the sessions included: treating sons and daughters equally; understanding the physical and emotional changes that happen in adolescence to girls and boys; creating self-confidence among adolescent sons and daughters; communicating with and understanding the problems of sons and daughters; understanding the importance of enabling sons and daughters to build peer networks and to spend time with friends; delaying the marriage of daughters; girl-boy attractions in adolescence and dealing with attractions; contraception; HIV/AIDS; harassment of and violence against girls; substance abuse and how to deal with it; stress and how to deal with it and understanding conflicting situations that arise between parents and adolescents. In addition, parents were invited to bring one or more of their adolescent children aged 13-17 to attend four sessions in which both parents and adolescents participated.

The project followed a pre-post evaluation research design, and panel surveys were conducted among mothers and fathers of adolescent boys and girls as well as among adolescent boys and girls themselves. Surveys were conducted prior to the implementation of intervention activities (baseline survey) and at its conclusion (endline survey) to evaluate the acceptability and effects of intervention activities on attitudes and behaviours of parents of 13-17-yearold adolescents and on adolescents themselves. Follow-up rates for the endline survey were excellent (over 95 percent among mothers and 86-89 percent among fathers, daughters and sons). A total of 457 mothers, 307 fathers, 322 daughters and 374 sons were interviewed in both the baseline and the endline survey.

\section{Study context}

Parents in study settings were poorly educated and economically disadvantaged. Socialisation practices were gendered and relatively authoritarian. Considerable proportions of parents did not encourage their sons and daughters to exercise agency in everyday matters, and girls were particularly restricted in exercising agency. Many parents had used violence to discipline their sons and daughters in the six months preceding the interview (while one in eight fathers reported beating their daughters, about two in five fathers reported beating their sons and two in five mothers reported beating their sons and daughters). Finally, although the majority of parents had spent time interacting with their children, between one in five and one in eight had not even spent time on a regular basis talking with their children in the month preceding the interview. 
Communication with children was limited. Indeed, communication was far from universal even about family matters. It was particularly limited with regard to SRH matters. Hardly any mother or father had discussed how pregnancy occurs, or talked about contraception and HIV-related issues with their children, nor had they discussed nocturnal emission with their sons. While not a single father had discussed menstruation with their daughter, some two-thirds of mothers had done so, but the content of this discussion focused overwhelmingly on the mechanics of using the "cloth" and instructions about not entering a temple or the kitchen during menstrual cycles. Many obstacles inhibited parents from educating their children about sexual and reproductive matters. These included a strong adherence to traditional norms that suggest that it is culturally inappropriate for parents to discuss SRH matters with their children and a deep concern that discussing these matters with a child would encourage the child to engage in sexual relations. Parents' own feelings of discomfort and shyness about talking about these matters with their adolescent children, along with their perceptions that their children would be equally shy to approach their parents and parents' own lack of awareness about these matters further inhibit communication on $\mathrm{SRH}$.

\section{Programme acceptability}

Exposure to the intervention was limited. Although two-thirds of mothers and half of fathers of adolescents aged 13-17 were aware of the intervention, just 27 percent of mothers and 17 percent of fathers had participated in the intervention. While participating parents were, by and large, similar to those who had not participated in the intervention, we note that participating mothers were more likely to come from poorer households and more likely to be engaged in wage-earning activities than non-participating mothers.

Among parents who had participated in the intervention, moreover, session attendance was far from universal, with just two-thirds ( 65 percent) of participating mothers and not even two-fifths (36 percent) of participating fathers reporting that they had attended 8 or more of the 16 sessions, with each session covering a topic included in the curriculum, and only 27 percent of mothers and 8 percent of fathers reporting that they had attended all sessions covering the16 topics included in the curriculum. The gender divide was evident, with fathers far less likely than mothers to have attended intervention activities regularly.

Although participating fathers had attended fewer sessions than had participating mothers, their assessment of the quality of the intervention was, for the most part, similar. Almost all mothers and fathers reported that all the topics to which they had been exposed were useful and 84-87 percent of mothers and fathers reported that they had learned new things in all the sessions they had attended. Somewhat fewer-71percent of mothers and 48 percent of fathers-reported that they had been exposed to information for the first time in all the sessions they had attended. Clearly, fathers, who were better educated and less confined to the home, had multiple sources of information about adolescent health and development and SRH matters. Finally, although peer facilitators made efforts to reduce discomfort when such topics as communicating about physical maturation, pregnancy and contraception with children were discussed, only 66 percent each of mothers and fathers reported that they did not feel shy or uncomfortable in any of the sessions they had attended.

While 27 percent of mothers and 17 percent of fathers had participated in the intervention, just 21 percent of (all) mothers and even fewer fathers-13 percent-reported that their son or daughter had attended even one of the joint sessions. Adolescents' reports mostly corroborated the reports of parents: just 23 percent of daughters and 21 percent of sons who were interviewed for the endline survey reported that they or their sibling had attended at least one joint session, and only 15-16 percent reported that they had attended all four sessions. Interviewed adolescents who had attended the intervention did, however, assess the programme favourably in terms of its usefulness (99 percent of daughters and 98 percent of sons), imparting of new information (89 percent of daughters and 97 percent of sons) and delivery in ways that minimised discomfort ( 72 percent of daughters and 75 percent of sons).

\section{Programme effectiveness on changing parents' knowledge and attitudes}

In general, findings show that effects of the intervention on parents' knowledge and attitudes were mixed and gendered. There were positive effects of the intervention on indicators such as parental awareness of SRH matters and certain parental attitudes. Parents had become more favourable to involving children in decisions about their own lives and informing children about sexual and reproductive matters. At the same time, these positive effects were 
observed in just a few instances of parental awareness and attitudes-in-depth awareness of condoms, awareness about HIV/AIDS among mothers, awareness about pregnancy-related matters and emergency contraception among fathers, mothers' attitudes about involving sons and daughters in the choice of marriage partner and about communicating on various sensitive matters with their daughters and, to a lesser extent, sons. Findings showed no effects on other issues, including parental awareness of other contraceptives, physical maturation issues, legal age for marriage and sex and pregnancy matters. Again, no effects attributable to exposure to the intervention were observed with regard to parents' gender-role attitudes. Moreover, where positive effects of exposure to the intervention were observed, they were more likely to have been observed among mothers than fathers.

\section{Programme effectiveness on changing parents' practices with regard to socialisation of and communication with sons and daughters}

With regard to socialisation practices or communication with their children, although some positive effects were observed, the intervention fell short of changing socialisation practices of mothers and fathers or communication with their children. Socialisation practices remained gendered, and communication about sensitive SRH matters was rare as seen in both the baseline and the endline survey, with regard to both sons and daughters, and among mothers and fathers who had participated in the intervention and those who had not. Findings underscore huge challenges in breaking down strongly held traditional norms and in translating mothers' newly gained knowledge and favourable attitudes into practice.

Adolescent sons and daughters, by and large, reiterated the reports of their parents. Sons were significantly less likely to report in the endline survey than in the baseline survey that their father and mother had beaten them, and declines were particularly notable among those whose parents had participated in the intervention. Sons reported limited interaction with parents, for the most part, both in the baseline and in the endline survey. However, significantly more daughters reported in the endline survey than they did in the baseline survey interaction with their mother. On the whole, parents' exposure to the intervention had some effect on sons' reports of declines in the experience of violence perpetrated by their mother and father and on daughters' reports of interaction with their mother. Parentchild communication, as reported by sons and daughters, did not change over the course of the intervention.

Results were indeed disappointing and have highlighted that the intervention did not have a consistent effect, particularly among fathers, in changing awareness, attitudes or socialisation and communication practices.

\section{Implementing the intervention: Challenges faced}

We faced a number of challenges in implementing the intervention. First, the limited interest in an intervention on parenting in this gendered and hierarchical socio-cultural context made it difficult for programme implementers to convince parents about how exposure to an intervention that focused on building better parenting skills and improving parents' ability to communicate with and maintain close relations with adolescent children may benefit their children's health and development. As a result, large proportions of eligible parents did not agree to join the intervention, many who were enrolled did not attend regularly and those who did attend often suggested that the topic was irrelevant for them or that they would attend if the intervention was linked with livelihood opportunities. Fathers, in particular, were sceptical about the usefulness of the intervention, and it was often difficult to convey new ideas to mothers and fathers, especially those that involved communicating with children about SRH matters and those that called for greater exercise of agency among girls.

Second, despite the team's best efforts, it was difficult to reach all community members with adolescent children to inform them about the intervention. In this poor rural setting, many parents worked long hours in agriculture or in jobs that required commuting to nearby urban areas. Reaching them in the daytime and even in evenings was often difficult. Even when available, housework commitments among mothers and alcohol consumption among fathers (and a few mothers) made it difficult to access many parents. Some fathers, moreover, had temporarily migrated away from the village and were not in residence for much of the time during which the intervention was implemented. As such, project teams were unable to reach all parents to inform them about the study and were unable to arrive at an acceptable time when sessions could be held. As a result of lack of time, not all parents, particularly fathers, who had enrolled in the intervention attended most of its sessions. 
Third, in several cases, other adult family members attended the sessions instead of the enrolled parent. As a result, focused attention on parents was not achieved in most groups.

Fourth, it was difficult to identify local women and men who displayed both leadership qualities and willingness to undertake the role of peer facilitators. CEDPA India and GMUS made a concerted effort to identify appropriate facilitators, build their skills and support them at all stages of the intervention. However, there was considerable turnover among these peer mentors, and several peer mentors who agreed to take on the responsibility found it difficult to communicate intervention messages in a simple and convincing way.

Finally, we note that this was a 16-session pilot and, perhaps, in a setting as conservative as rural Bihar, the relatively short duration of the intervention was insufficient to bring about changes in parental and community norms and practices.

\section{Evaluation limitations}

Results have highlighted that the intervention did not have a consistent effect, particularly among fathers, in changing awareness, attitudes or socialisation and communication practices. The several challenges discussed above have clearly contributed to this limited effect. At the same time, we note that both those exposed to the intervention and those who were not so exposed were not entirely independent of each other as the participants and non-participants came from the same villages in which the intervention was implemented and that the effect of the intervention may well have reached non-participants, albeit indirectly. In other words, some of the observed increases in outcome indicators among non-participants may not be entirely independent of the intervention.

\section{Recommendations}

Although findings were disappointing, this should not be interpreted as a justification for closing the door on further efforts to engage parents and build positive parenting skills. Several lessons can be drawn from the experience of implementing our intervention for parents that are relevant for future programmes intended to strengthen the role of parents in ensuring healthy transitions to adulthood for adolescents.

\section{Review strategies for reaching parents}

Our findings have underscored that delivering an intervention through group sessions organised at village settings may not be an appropriate strategy. Many parents, fathers in particular, were seasonal migrants and had spent long hours at work or commuting to and from work or had spent leisure hours consuming alcohol, and despite the flexibility in scheduling meetings to suit them, many did not find it convenient to attend meetings early in the morning or late at night. Some other strategies that may be considered to attract mothers and fathers may include school-based interventions in which the health and development of children is linked with children's performance in school; linking sessions on parenting with ongoing self-help group meetings for women; combining parenting sessions with livelihood training activities or other activities in which parents express interest, and reaching parents with messages delivered through mobile phones and so on.

\section{Provide creative opportunities for parent-child interaction}

The intervention made significant efforts to promote parent-child interaction within the context of formal sessions. Four joint sessions were held in which the parent was invited to bring his or her son or daughter. While sons and daughters did attend at least one session, few attended all four, and perhaps a session conducted in classroom-like atmosphere was not conducive to establishing closer interaction. Efforts may be made to take parent-child dyads on outings in which parenting messages are interspersed with joint activities. At the same time, it may be useful, during the intervention, to give parents the task of putting new parenting practices or communication skills into effect in the home environment and reporting back on successes and challenges faced. 


\section{Initiate parenting programmes for parents of younger children}

As the literature will confirm, adolescents are in a phase where they begin to make efforts to exercise independence, develop new ideas, shed ideas promoted by their parents and conceal their thoughts and actions from their parents. In that sense, an inference that may be drawn from our findings is that while parents of adolescents in these ages may be the most in need of exposure to new parenting skills, an intervention is likely to be more strategic for parents of younger children-those aged 10-12-to prepare them to build closer relationships and more effective communication with children so as to provide constructive support to adolescents as they transition into adult roles. Parents of younger adolescents may be more easily reachable than those of older adolescents-almost all will be in school-and children themselves may be more open to strengthening their links with their parents.

\section{Assess the ideal duration of a parenting intervention}

The evidence that very few parents had attended all sessions raises questions about the ideal duration of a parenting intervention. On the one hand, our intervention was too short to change parents' attitudes and parenting practices; on the other, it was too long to sustain interest and regular participation. Efforts need to be made to better understand how to tailor an intervention to respond to both of these opposing forces. It needs to be assessed, for example, whether changes in the intervention (based on experiences from our study), such as stripping it of some of the sessions and interspersing lecture-type sessions with activities that would sustain participants' interest, could contribute to achieving the aims of the intervention. Also if such an intervention were to achieve its goals, it needs to be seen whether it would succeed in breaking down traditional norms about hierarchical parent-child relationships and limited parent-child communication about physical maturation and SRH matters.

\section{Include role model parents to discuss their experiences}

Role models-parents who have deviated from traditional norms and have communicated openly with their sons and daughters-may be an effective confidence-building measure to reassure parents that close parent-child relations and open communication about SRH matters have not led boys and girls astray and that, on the contrary, these young people have made successful transitions into further education, employment and other leadership positions. Including sessions with such parents in the intervention may be effective in allaying fears about the unacceptability of parent-child communication.

\section{Breaking down strongly held norms requires reaching communities more generally}

It is clearly challenging to change strongly held norms regarding hierarchical parent-child relations, socialisation practices that enable adolescents to exercise agency in everyday matters and communication about physical maturation and SRH matters in a society in which communities adhere so strongly to these norms. Our experience suggests that it may not be enough to expose a few parents to new ideas, but that broader community engagement may be necessary. Efforts to elicit the support of influential people of the community and local leadership and to hold other community-level BCC (behavior change communication) events may be needed in order to enable parents of adolescent children to gain confidence about engaging in new practices.

In short, our findings confirm the need to build parents' awareness of physical maturation and SRH matters, change parents' attitudes on gender roles, socialisation of sons and daughters and parent-child communication and enable parents to interact more freely and communicate about sensitive matters with their adolescent children. While our findings relating to the effectiveness of one such intervention are somewhat disappointing, we note that our intervention model was acceptable to many mothers and fathers exposed to it. Furthermore, as a pilot, one of the first of its kind to be implemented in India, it has provided some important lessons for future implementation. 


\section{Appendix 1 \\ Calculation of standard of living index}

Household economic status was measured using a standard of living index composed of household asset data on ownership of selected durable goods, including means of transportation, as well as data on access to a number of amenities. The standard of living index was constructed by allocating the following scores to a household's reported assets or amenities:

Type of house: 2 for pucca; 1 for semi-pucca; 0 for kachcha.

Agricultural land owned: 1 for yes; 0 for no.

Access to toilet facility: 4 for own toilet; 2 for public or shared toilet; 0 for no facility.

Fuel for cooking: 2 for electricity, liquid petroleum gas, or biogas; 1 for coal/charcoal/kerosene/wood/crop residue/ dung cakes; 0 for other fuels.

Source of drinking water: 4 for own piped water, hand pump, covered well; 3 for own open well; 2 for public or shared piped water, hand pump or covered well; 1 for public/shared open well; 0 for other water sources.

Access to electricity: 3 for electricity; 0 for no electricity.

Ownership of different durable goods: 4 each for car/truck, thresher, tractor; 3 each for motor cycle/scooter, refrigerator, computer/laptop, landline/mobile, colour television; 2 each for bicycle, electric fan, radio/transistor, black and white television, sewing machine, water pump, animal drawn cart; 1 for a watch/clock

The index score, so constructed, ranged from 0 to 58. 


\section{Appendix 2 \\ Background characteristics of parents by exposure to the intervention (had attended at least two sessions), baseline survey}

\begin{tabular}{|c|c|c|c|c|c|c|}
\hline & \multicolumn{3}{|c|}{ Mothers } & \multicolumn{3}{|c|}{ Fathers } \\
\hline & $\begin{array}{l}\text { Non- } \\
\text { participants }\end{array}$ & Participants & Combined & $\begin{array}{l}\text { Non- } \\
\text { participants }\end{array}$ & Participants & Combined \\
\hline Number of parents & 340 & 117 & 457 & 255 & 52 & 307 \\
\hline Education [median] & NC & NC & NC & 9.0 & 9.0 & 9.0 \\
\hline Standard of living index [mean] & 17.7 & $15.5^{* * *}$ & 17.1 & 15.8 & 15.9 & 15.8 \\
\hline Mean age & 40.6 & 40.5 & 40.6 & 46.9 & 45.8 & 46.7 \\
\hline \multicolumn{7}{|l|}{ Caste (\%) } \\
\hline SC/ST & 14.1 & 34.2 & 18.1 & 21.2 & 30.8 & 22.7 \\
\hline OBC & 58.5 & 52.1 & 58.4 & 56.1 & 34.6 & 53.2 \\
\hline General & 27.4 & 13.7 & 23.6 & 22.7 & 34.6 & 24.1 \\
\hline \multicolumn{7}{|l|}{ Religion (\%) } \\
\hline Hindu & 90.9 & 95.3 & 92.1 & 93.2 & 95.6 & 93.6 \\
\hline \multicolumn{7}{|l|}{ Work (\%) } \\
\hline $\begin{array}{l}\text { Engaged in paid or unpaid work in } \\
\text { the last year }\end{array}$ & 41.7 & $56.5^{* *}$ & 45.7 & 98.2 & 95.9 & 97.8 \\
\hline
\end{tabular}

Note: $\sim p<=0.10,{ }^{*} p<=0.05,{ }^{* *} p<=0.01,{ }^{* *} p<=0.001$. Independent samples t-test/chi-square test showing the significant differences in the means/distribution between participants and non-participants. NC: Median cannot be calculated. 


\section{References}

Abraham, L. and K. A. Kumar. 1999. "Sexual experiences and their correlates among college students in Mumbai city, India”. International Family Planning Perspectives, 25(3): 139-46.

Acharya, R., S. Kalyanwala, S. J. Jejeebhoy et al. 2009. Broadening girls' horizons: Effects of a life skills education programme in rural Uttar Pradesh. New Delhi: Population Council.

Alexander, M., L. Garda, S. Kanade et al. 2006. Formation of Partnerships among Young Women and Men in Pune District, Maharashtra. New Delhi: Population Council.

Ashenfelter, O. 1978. “Estimating the Effect of Training Programs on Earnings”. Review of Economics and Statistics, 60(1):47-57.

Ashenfelter, O and D. Card. 1985. "Using the Longitudinal Structure of Earnings to Estimate the Effect of Training Programs". Reviews of Economics and Statistics, 67(4):648-60.

Centre for Development and Population Activities (CEDPA). 2000. Better Life Options: India Program Evaluation. New Delhi: CEDPA.

Diop, N. J. and A. Diagne. 2008. Improving the communication between parents and adolescent in reproductive health and HIV/ AIDS. Final Report. Dakar: Population Council.

International Institute for Population Sciences (IIPS) and Macro International. 2008. National Family Health Survey (NFHS-3), India, 2005-06: Bihar. Mumbai: IIPS.

International Institute for Population Sciences (IIPS), 2010. District Level Household and Facility Survey (DLHS-3), 2007-08: India. Bihar: Mumbai: IIPS.

International Institute for Population Sciences (IIPS) and Population Council. 2010. Youth in India: Situation and Needs 20062007. Mumbai: IIPS.

Jejeebhoy, S. J and K. G. Santhya. 2011. Parent-child communication on sexual and reproductive health matters: Perspectives of mothers and fathers of youth in India. New Delhi: Population Council.

Kish, L. 1949. “A procedure for objective respondent selection within the household”. Journal of the American Statistical Association, 44: 380-87.

Lambert, H. and K. Wood. 2005. "A comparative analysis of communication about sex, health and sexual health in India and South Africa: Implications for HIV prevention". Culture, Health and Sexuality, 7(6): 527-41.

Mehra, S., R. Savithri and L. Coutinho. 2002. "Sexual behaviour among unmarried adolescents in Delhi, India: Opportunities despite parental controls”, Paper presented at the 2002 IUSSP Regional Population Conference, Bangkok, June.

Ministry of Health and Family Welfare (MOHFW). 2006. Implementation Guide on RCH II Adolescent Reproductive Sexual Health Strategy for State and District Programme Managers. New Delhi:

MOHFW, Government of India.

Ministry of Health and Family Welfare (MOHFW). 2014. Rashtriya Kishor Swasthya Karyakram Strategy Handbook. New Delhi: MOHFW, Government of India.

Office of the Registrar General, India. 2013. Special bulletin on maternal mortality in India 2010-12. Sample Registration System. Accessed on 8 May, 2014 at http://www.censusindia.gov.in/vital_statistics/SRS_Bulletins/MMR_Bulletin-2010-12.pdf.

Office of the Registrar General and Census Commissioner, India. 2013. Census of India 2011: Primary Census Abstract, Data Highlights, India, Series 1. New Delhi: Office of the Registrar General and Census Commissioner, India. Accessed on 25 March, 2014 at http://www.censusindia.gov.in/2011census/PCA/PCA_Highlights/pca_highlights_india.html.

Office of the Registrar General and Census Commissioner, India. n.d. a. Primary Census Abstract, Bihar. Accessed on 8 May, 2014 athttp://www.censusindia.gov.in/2011census/population_enumeration.aspx.

Office of the Registrar General and Census Commissioner, India. n.d. b. Single Year Age Data-C13 Table (India/States/UTs). Accessed on 8 May, 2014 at http://www.censusindia.gov.in/pca/default.aspx. 
Office of the Registrar General and Census Commissioner, India. n.d. c. Annual Health Survey 2011-12, Fact Sheet, Bihar. Accessed on 8 May, 2014 at http://www.censusindia.gov.in/vital_statistics/AHSBulletins/AHS_Factsheets_2011_12/Bihar_ Factsheet_2011-12.pdf

Population Council. 2013. The feasibility, acceptability and effectiveness of a safe spaces intervention for school-going girls in Pune district, Maharashtra, India. New Delhi: Population Council. (Unpublished report).

Shekhar, M., S. Ghosh and P. Panda. 2007. "Exploring safe sex awareness and sexual experiences of adolescents in Patna". Economic and Political Weekly, 42(48): 48-55.

Vandenhoudt, H.A., K. S. Miller, J. Ochura et al. 2010. "Evaluation of a US evidence-based parenting intervention in rural Western Kenya: From Parents Matter! to Families Matter!” AIDS Education and Prevention, 22(4): 328-43.

World Health Organisation (WHO). 2007. Helping parents in developing countries improve adolescents' health. Geneva: World Health Organisation. 


\section{Authors}

Shireen J Jejeebhoy, Senior Associate, Population Council, New Delhi

A J Francis Zavier, Senior Programme Officer, Population Council, New Delhi

K G Santhya, Associate II, Population Council, New Delhi

Santosh Kumar Singh, Assistant Programme Officer, Population Council, Patna, Bihar

Rajib Acharya, Associate I, Population Council, New Delhi

Aparajita Gogoi, Executive Director, CEDPA India

Vinita Nathani, Senior Advisor, Youth, CEDPA India 


\section{List of investigators}

Shabnam Begum

Kamini Devi

Ajay Kumar Dubey

Arsee Fatima

Sulekha Gautam

Raj Kamal

Deepak Kumar

Anita Kumari

Diwakar Maji

Bhaskar Mishra

Hrishikesh Pandey

Alok Kumar Pandey

Renu Kumari Prabha

Brahmanand Saraswati

Srikant Singh

Ram Shankar

Deepu Kumar Sharma

Jai Shankar Tiwari

Sheela Verma 
Printed at:

systemsvision@gmail.com 
Zone 5A, Ground Floor India Habitat Centre, Lodi Road New Delhi, India 110003 Phone: 91-11-24642901 Email: info.india@popcouncil.org

Ideas. Evidence. Impact. 